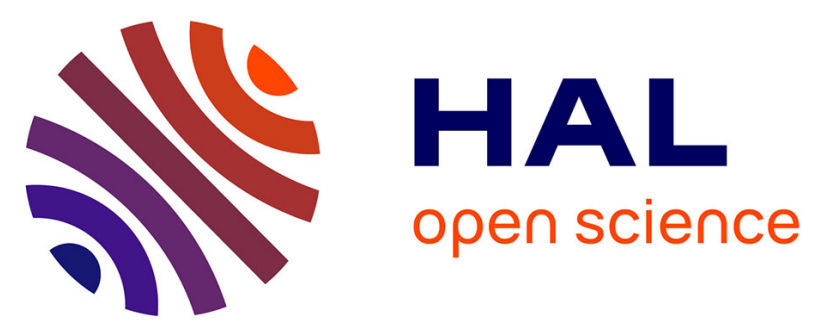

\title{
Tracking Magmatic Hydrogen Sulfur Circulations Using Electrical Impedance: Complex Electrical Properties of Core Samples at the Krafla Volcano, Iceland
}

Léa Lévy, Benoit Gibert, F. Sigmundsson, D. Deldicque, Fleurice Parat, G.P. Hersir

\section{To cite this version:}

Léa Lévy, Benoit Gibert, F. Sigmundsson, D. Deldicque, Fleurice Parat, et al.. Tracking Magmatic Hydrogen Sulfur Circulations Using Electrical Impedance: Complex Electrical Properties of Core Samples at the Krafla Volcano, Iceland. Journal of Geophysical Research : Solid Earth, 2019, 124 (3), pp.2492-2509. 10.1029/2018JB016814 . hal-02127430

\section{HAL Id: hal-02127430 \\ https://hal.umontpellier.fr/hal-02127430}

Submitted on 21 May 2019

HAL is a multi-disciplinary open access archive for the deposit and dissemination of scientific research documents, whether they are published or not. The documents may come from teaching and research institutions in France or abroad, or from public or private research centers.
L'archive ouverte pluridisciplinaire HAL, est destinée au dépôt et à la diffusion de documents scientifiques de niveau recherche, publiés ou non, émanant des établissements d'enseignement et de recherche français ou étrangers, des laboratoires publics ou privés. 


\section{JGR Solid Earth}

\author{
RESEARCH ARTICLE \\ 10.1029/2018JB016814 \\ Key Points: \\ - Pyrite, iron oxides, smectite, and \\ pore fluid conductivity influence the \\ electrical impedance phase angle of \\ volcanic rocks \\ - Volcanic rocks with high maximum \\ phase angle contain pyrite if the real \\ conductivity is also high \\ - For a given pyrite content, the \\ maximum phase angle decreases \\ with increasing smectite content
}

Supporting Information:

- Supporting Information S1

- Table S1

- Table S2

- Data Set S1

Correspondence to:

L. Lévy,

lea.levy@ens.fr

Citation:

Lévy, L. E., Gibert, B., Sigmundsson,

F., Deldicque, D., Parat, F., \&

Hersir, G. P. (2019). Tracking

magmatic hydrogen sulfur circulations

using electrical impedance: Complex

electrical properties of core samples at

the Krafla volcano, Iceland. Journal

of Geophysical Research:

Solid Earth, 124, 2492-2509.

https://doi.org/10.1029/2018JB016814

Received 2 OCT 2018

Accepted 15 FEB 2019

Accepted article online 22 FEB 2019

Published online 9 MAR 2019

Corrected 25 APR 2019

This article was corrected on 25 APR 2019. See the end of the full text for details.

\section{Tracking Magmatic Hydrogen Sulfur Circulations Using Electrical Impedance: Complex Electrical Properties of Core Samples at the Krafla Volcano, Iceland}

\author{
L. Lévy ${ }^{1,2}(\mathbb{D})$, B. Gibert ${ }^{3}$, F. Sigmundsson ${ }^{2}(\mathbb{D})$, D. Deldicque ${ }^{1}$, F. Parat ${ }^{3}$, and G. P. Hersir ${ }^{4}$ \\ ${ }^{1}$ Laboratoire de Géologie, Ecole Normale Supérieure-PSL, CNRS, Paris, France, ${ }^{2}$ Nordic Volcanological Center, Institute \\ of Earth Sciences, University of Iceland, Reykjavík, Iceland, ${ }^{3}$ CNRS, Géosciences Montpellier, Université de \\ Montpellier, Montpellier, France, ${ }^{4}$ ÍSOR-Iceland GeoSurvey, Reykjavík, Iceland
}

\begin{abstract}
Interaction of $\mathrm{H}_{2} \mathrm{~S}$ escaping from magma and basaltic rocks leads to pyrite mineralization, witnessing active hydrothermal circulation. We study the possibility to track this process using geoelectrical methods. Complex conductivity spectra of 30 core samples from the Krafla volcano, Iceland, measured in the laboratory, indicate that pyrite can be discriminated from other minerals present in volcanic environments, such as iron oxides and clays. Joint evaluation of the maximum phase angle of electrical impedance and its real part at low frequency is required. The volume of metallic particles (pyrite or iron oxides) can be estimated from the maximum phase angle, but a decrease of the maximum phase angle with increased fluid conductivity or smectite volume is also observed and needs to be considered in the estimation. The laboratory observations can guide interpretation of field observations for estimation of pyrite volume in volcanic environments.
\end{abstract}

Plain Language Summary Hydrogen sulfur is a magmatic gas flowing under volcanoes. Its presence indicates ongoing geothermal activity, a clean and efficient source of energy. Upon exploitation of geothermal energy, this gas is extracted and needs to be reinjected in order to limit the environmental impacts. When hydrogen sulfur flows underground, a mineral forms by chemical transformation of the rock: pyrite. Therefore, pyrite indicates both where geothermal activity is and if hydrogen sulfur has been sequestrated upon reinjection. In order to track pyrite with geoelectrical methods, we study here the electrical signature of 30 natural samples from the Krafla volcano (Iceland): the capacity of the samples to both transfer and store electrical charges (conduction and polarization). Volcanic samples contain other minerals sensitive to electrical stimulation: iron oxides and smectite. Based on mineral quantification of pyrite, smectite, and iron oxides in the 30 samples, as well as on polarization and conduction measurements in a large range of frequency, we show that conduction at low frequency and maximum polarization are enough to discriminate pyrite from iron oxides. We also show that the volume of pyrite can be estimated from the maximum polarization but that an abundance of smectite tends to reduce this maximum, for a given pyrite volume.

\section{Introduction}

Hydrogen sulfur $\left(\mathrm{H}_{2} \mathrm{~S}\right)$, gas of magmatic origin, flows naturally toward the surface in volcanic areas but is also a by-product of geothermal energy exploitation, contributing to air pollution (Júlíusson et al., 2015). As basaltic rocks contain iron, pyrite $\left(\mathrm{FeS}_{2}\right)$ can easily form when $\mathrm{H}_{2} \mathrm{~S}$-enriched fluids interact with a basaltic matrix in magmatic hydrothermal systems (Stefánsson et al., 2011). Libbey and Williams-Jones (2013) suggest that pyrite mineralization, as a witness of upflow zones, can help delineate the location of high-enthalpy geothermal reservoirs. The abundant presence of pyrite at deeper levels than the shallow discharge zone has also been observed to correlate to the presence of aquifers (Gudmundsson et al., 2010). Therefore, mapping pyrite distribution in a geothermal reservoir can constrain its current activity. Monitoring the evolution of pyrite mineralization with time may also help demonstrate the success of $\mathrm{H}_{2} \mathrm{~S}$ sequestration based on injection of waste water from geothermal power plants into basaltic rocks (Prikryl et al., 2018) and thus be valuable for the social acceptation of geothermal utilization.

Detecting underground massive metallic ore deposits and discriminating disseminated sulfides, veinlets sulfides and graphite is feasible by means of induced polarization (IP) field measurements (Börner et al., 2018;
(C)2019. American Geophysical Union. All Rights Reserved. 
Pelton et al., 1978; Placencia-Gómez, 2015). The reorganization of charges, at the interface between pore fluid and metallic particles (or negatively charged particles, such as clay minerals), creates local electrical "displacement" currents, which add up until a steady maximum voltage is reached. The time delay between maximum voltage and maximum current, also known as the phase angle for sinusoidal signals, is a measure of the polarization (Bücker et al., 2018; Chelidze \& Gueguen, 1999; Olhoeft, 1985). Strong polarization effects are in particular associated to disseminated metallic particles (e.g., pyrite or magnetite) because of their semiconducting properties. Under an external electric field, electrons can rapidly redistribute within the metallic particle in response to the external field (e.g., Pridmore \& Shuey, 1976; Shuey, 1975). This redistribution causes accumulation of ions at the interface between fluid and metallic particles. Several models have been developed to describe how ions reversibly accumulate at the interface between pore fluid and metallic particles, causing polarization. Such models use either analytical equations for simple geometries (e.g., Misra et al., 2016; Placencia-Gómez \& Slater, 2016; Revil et al., 2015; Wait, 1987; Wong, 1979) or numerical finite-element solutions to equations describing the physics involved (e.g., Abdulsamad et al., 2017; Bücker et al., 2018). Some of these models successfully predict the low-frequency $\left(f \leq 10^{4} \mathrm{~Hz}\right)$ complex conductivity of synthetic samples containing disseminated metallic particles in an electrolyte (e.g., Abdulsamad et al., 2017; Revil et al., 2017; Wong, 1979). However, these models typically assume that metallic particles are not connected to each other, whereas the connectivity of metallic particles may cause conduction rather than polarization. Down-hole electrical logging and laboratory electrical measurements on core samples from drill holes 735B and 1105A, at the Southwest Indian Ridge, suggest that the presence of abundant (20-30\%) and connected iron and titanium oxides in mid-ocean ridge gabbros can contribute to up to $80 \%$ of the measured electrical conductivity, by electronic conduction (Einaudi et al., 2005; Pezard et al., 1991).

Rock polarization is also sensitive, to a lesser extent, to the pore size, the presence of clay minerals, and the electrolyte conductivity, especially in the case of sandstones (Binley et al., 2005; Klein \& Sill, 1982; Kruschwitz, 2007; Kruschwitz et al., 2010; Leroy et al., 2017; Lesmes \& Frye, 2001; Revil \& Skold, 2011; Slater \& Sandberg, 2000; Weller \& Slater, 2012; Weller et al., 2013). Similarly to connected metallic particles, connected clay minerals may also prevent polarization and cause conduction instead. Indeed, the largest IP effects associated with clay minerals in sedimentary rocks are considered to occur when clay contents are in the range 3-10\%, while lesser effects are observed for higher percentages, interpreted as the onset of conduction throughout connected clay pathways (e.g., Parkhomenko, 1971; Telford et al., 1990; Vinegar \& Waxman, 1984).

Magmatic hydrothermal systems differ from typical economical sulfide ore deposits in that sulfides are present in lower concentration. Moreover, the presence of iron oxides from magmatic crystallization, the high temperature of pore fluids, and the abundance of clay minerals, including the very conductive clay mineral smectite (Lévy et al., 2018), may complicate significantly the detection and quantification of sulfide mineralization. In order to provide geothermal industry with constraints for geophysical interpretations of field IP measurements, at exploration or $\mathrm{H}_{2} \mathrm{~S}$ sequestration stages, the information contained in the IP response of rocks in these environments requires a better understanding. Sulfides grain sizes in natural samples may also span a larger range than synthetic samples, which complicates the analysis of IP parameters. In order to bridge the gap between field studies and theoretical models tested on synthetic samples, we provide here an analysis of the complex electrical properties of natural samples from an active volcanic area. Our approach is to investigate if relationships between IP parameters and mineral parameters can be observed for a set of heterogeneous and very different natural volcanic rocks (wide range of iron oxides, sulfides and smectite volumes, and different mineral textures), representative of the variability found in natural volcanic environments like the Krafla volcano. Rather than using theoretical model to interpret our data, we here analyze the influence of mineralogy on two simple IP parameters, which can be retrieved both in the laboratory and in the field: the maximum phase angle (MPA) and the bulk real conductivity at $1 \mathrm{~Hz}$.

\section{Materials and Methods}

\subsection{Rock Samples}

Eighty-eight core samples from four boreholes at the Krafla volcano, Iceland, were available for this study. The host rock varies from basaltic glass of hyaloclastite type to crystalline basalt of dolerite type (Gautason et al., 2007; Gudmundsson, 1991; Jónsson et al., 2003). The dominant primary minerals from magmatic crystallization are plagioclases, pyroxenes, and iron-titanium-oxides (titanomagnetite, rutile, and ilmenite). 
The alteration level varies from fully altered glassy samples, where clay minerals dominate, often accompanied by zeolites, quartz, and calcite, to almost fresh crystalline samples, with an abundance of unaltered plagioclase phenocrysts.

Cylindrical plugs, with average length of $30 \mathrm{~mm}$ and average diameter of $25 \mathrm{~mm}$, were prepared for electrical measurements and saturated under vacuum with water containing six distinct $\mathrm{NaCl}$ concentrations, resulting in fluid conductivities ranging from 0.02 to $11 \mathrm{~S} / \mathrm{m}$. Measurements at each fluid conductivity were carried out in average 30 days after changing the $\mathrm{NaCl}$ concentration. Indeed, monitoring of the bulk conductivity showed a steady value after 30 days (less than 5\% relative change over 6 weeks for most samples). Therefore, we consider that the salinity inside the pore spaces is homogenized after 30 days (see Figure S2 in the supporting information). The saturating procedure and measurements of porosity, density and cation exchange capacity (CEC), as well as bulk real conductivity at all fluid conductivities, are presented for these 88 samples in Lévy et al. (2018).

Among these 88 samples, 30 samples with varying complex electrical properties were selected in this study for further analysis of the sulfides and iron-titanium-oxide minerals and comparison to the complex electrical signature. For each plug, thin sections were prepared either from one end of the plug (transverse section) or from the host core sample in the vicinity of the hole created by the plug (axial section).

\subsection{Analysis of the Mineralogy}

The chemistry of metallic particles was analyzed quantitatively by Electron Probe Micro-Analysis at Géosciences Montpellier and qualitatively by scanning electron microscope (SEM) at Ecole Normale Supérieure (Paris). As shown by the ternary diagram presented in Appendix B, most of the iron-titanium-oxide minerals analyzed belong to the titanomagnetite series, but a few oxides belong to the titanohematite series. Yet, these are located near the ilmenite-end rather than hematite-end. Indeed, no hematite was found in our samples. Considering a general structural formula $\mathrm{Fe}_{x} \mathrm{~S}_{1}$ for sulfides, most sulfides analyzed in our samples have $x$ in the range $0.63-0.67$, corresponding to pyrite. However, sulfide with $x=1.1$ occurs in more than half of the analyses in sample L41, corresponding to the composition of troilite, the Fe-rich end-member of the pyrite-pyrrhotite solid solution (Figure B1). For simplification, we will mostly refer to iron-titanium-oxide minerals and sulfide minerals by the terms titanomagnetite and pyrite, respectively. Our data set does not allow to distinguish the IP responses of titanomagnetite and ilmenite or those of pyrite and pyrrhotite.

The volume fraction of pyrite and titanomagnetite are estimated using SEM images of entire thin sections (width between 25 and $40 \mathrm{~mm}$ ). These images are processed using the freeware ImageJ (Abramoff et al., 2004). The fraction of the surface covered by metallic particles is estimated by adjusting the brightness threshold to count only metallic particles. With the resolution chosen for the analysis of whole thin sections, pixels at the edges of metallic particles have a brightness between metallic and nonmetallic. This introduces an uncertainty, which was evaluated by processing figures with two different brightness thresholds. Volume fractions, derived by extrapolation from the inferred surface fractions and assuming homogeneous rock samples, are presented in Table 1. Two samples, L41 and L82, have a particularly heterogeneous two-dimensional distribution of metallic particles (Figure 1 for sample L41). Therefore, two distinct cross-sectional areas of the plugs were analyzed and reported in Table 1.

Indeed, local heterogeneity cannot be avoided although the plugs have been prepared from homogeneous layers of the boreholes. This limits the accuracy of this method, but the overall uncertainty on the volume fraction was estimated to $30 \%$ in the most extreme cases (L41 and L82). Other quantification methods, such as X-Ray computed tomography density statistics, are problematic given the variability and complexity of the background mineralogy (Clennell et al., 2010). The method chosen here was considered as the most reliable for quantifying the volume fraction of metallic particles in natural samples.

For smectite quantification, a large fraction of the original sample was crushed and mixed, so that the uncertainty stemming from possible three-dimensional heterogeneity of a core is mitigated. The smectite volume is calculated from the CEC and the dry density of each sample, following equation (1).

$$
\mathrm{Smec}_{\mathrm{vol} . \%}=\frac{\mathrm{CEC}}{\mathrm{CEC}_{0}} \frac{\rho_{\mathrm{dry}}}{\rho_{\mathrm{smec}}}
$$

where CEC and $\mathrm{CEC}_{0}=91 \mathrm{meq} / 100 \mathrm{~g}$ are the CEC of the sample and of pure smectite, respectively, $\rho_{\text {smec }}=$ $2.3 \mathrm{~g} / \mathrm{cm}^{3}$ is the density of smectite, and $\rho_{\text {dry }}$ is the density of the dry sample. The value for $\mathrm{CEC}_{0}$ corresponds 
Table 1

Relevant Mineralogy Information Obtained From SEM and EPMA Analyses, As Well As Petrophysical Measurements

\begin{tabular}{|c|c|c|c|c|c|c|c|c|c|}
\hline $\begin{array}{l}\text { ID } \\
-\end{array}$ & $\begin{array}{c}\text { Rock type } \\
-\end{array}$ & $\begin{array}{c}\text { Major } \\
-\end{array}$ & $\begin{array}{c}v_{\min } \\
(\mathrm{vol} . \%)\end{array}$ & $\begin{array}{c}v_{\max } \\
(\operatorname{vol} . \%)\end{array}$ & $\begin{array}{c}\text { Smec } \\
\text { (vol.\%) }\end{array}$ & $\begin{array}{c}\text { Min MPA } \\
(\mathrm{mrad})\end{array}$ & $\begin{array}{c}\text { Max MPA } \\
\text { (mrad) }\end{array}$ & $\begin{array}{c}\sigma_{1 \mathrm{~Hz}, 0.13 \mathrm{~S} / \mathrm{m}} \\
(\mathrm{S} / \mathrm{m})\end{array}$ & $\begin{array}{c}\text { Porosity } \\
(\%)\end{array}$ \\
\hline L02 & welded breccia & Pyr & $4.8 \%$ & $5.4 \%$ & $12 \%$ & 36 & 62 & $2.55 \cdot 10^{-2}$ & $36.0 \%$ \\
\hline L06 & bas. breccia & Pyr & $2.3 \%$ & $2.5 \%$ & $30 \%$ & 62 & 94 & $2.35 \cdot 10^{-2}$ & $26.4 \%$ \\
\hline L09 & bas. breccia & Pyr & $3.2 \%$ & $3.6 \%$ & $38 \%$ & 36 & 44 & $5.99 \cdot 10^{-2}$ & $27.5 \%$ \\
\hline L14 & hyaloclastite & Pyr & $4.0 \%$ & $4.1 \%$ & $28 \%$ & 50 & 65 & $6.76 \cdot 10^{-2}$ & $39.5 \%$ \\
\hline L19 & dense lava & Pyr & $6.3 \%$ & $7.6 \%$ & $25 \%$ & 105 & 154 & $1.19 \cdot 10^{-2}$ & $21.6 \%$ \\
\hline L22 & ves. lava & Pyr & $1.8 \%$ & $2.1 \%$ & $27 \%$ & 64 & 93 & $4.50 \cdot 10^{-2}$ & $13.9 \%$ \\
\hline L24a & hyaloclastite & Pyr, Pyrrh & $5.4 \%$ & $6.0 \%$ & $31 \%$ & 59 & 90 & $5.25 \cdot 10^{-2}$ & $22.2 \%$ \\
\hline $\mathrm{L} 24 \mathrm{~b}$ & hyaloclastite & see L24a & see L24a & see L24a & see L24a & 56 & 84 & $4.36 \cdot 10^{-2}$ & $17.8 \%$ \\
\hline $\mathrm{L} 25$ & bas. breccia & Pyr & $4.4 \%$ & $4.8 \%$ & $12 \%$ & 83 & 127 & $5.04 \cdot 10^{-2}$ & $34.4 \%$ \\
\hline L31 & hyaloclastite & Pyr & $0.2 \%$ & $0.2 \%$ & $35 \%$ & 9 & 16 & $7.52 \cdot 10^{-2}$ & $23.6 \%$ \\
\hline L41 & bas. breccia & Troil, Pyr & $4.3 \%$ & $5.3 \%$ & $5 \%$ & 111 & 186 & $7.70 \cdot 10^{-3}$ & $11.3 \%$ \\
\hline L75 & ves. lava & Pyr, Hayc & $0.9 \%$ & $0.9 \%$ & $1 \%$ & 15 & 61 & $2.44 \cdot 10^{-3}$ & $24.7 \%$ \\
\hline L82 & bas. breccia & Pyr & $0.4 \%$ & $1.4 \%$ & $5 \%$ & 13 & 26 & $2.23 \cdot 10^{-2}$ & $34.1 \%$ \\
\hline L119 & hyaloclastite & Pyr & $0.2 \%$ & $0.2 \%$ & $51 \%$ & 7 & 11 & $5.64 \cdot 10^{-2}$ & $26.9 \%$ \\
\hline L123 & hyaloclastite & Pyr, Rut & $0.5 \%$ & $0.5 \%$ & $31 \%$ & 9 & 18 & $1.04 \cdot 10^{-1}$ & $36.5 \%$ \\
\hline L12a & dense lava & Ti-Mag & No analysis & No analysis & $7 \%$ & 51 & 74 & $2.82 \cdot 10^{-3}$ & $3.9 \%$ \\
\hline L12b & dense lava & see L12b & No analysis & No analysis & $7 \%$ & 42 & 68 & $2.27 \cdot 10^{-3}$ & $4.7 \%$ \\
\hline L21 & dense lava & Mag & $1.6 \%$ & $1.7 \%$ & $30 \%$ & 20 & 30 & $2.60 \cdot 10^{-2}$ & $14.9 \%$ \\
\hline L26 & ves. lava & Mag, Ilm & $1.1 \%$ & $1.5 \%$ & $18 \%$ & 34 & 37 & $1.39 \cdot 10^{-2}$ & $9.9 \%$ \\
\hline L30 & dyke & Mag, Ilm & $1.6 \%$ & $2.0 \%$ & $16 \%$ & 23 & 59 & $7.82 \cdot 10^{-3}$ & $5.0 \%$ \\
\hline L45 & ves. lava & see L46a & No analysis & No analysis & $1 \%$ & 20 & 89 & $1.14 \cdot 10^{-2}$ & $27.1 \%$ \\
\hline L46a & ves. lava & Mag, Ilm & $1.4 \%$ & $1.7 \%$ & $0 \%$ & 23 & 59 & $8.60 \cdot 10^{-3}$ & $24.4 \%$ \\
\hline L46b & ves. lava & see L46a & see L46a & see L46a & see L46a & 25 & 58 & $7.34 \cdot 10^{-3}$ & $23.4 \%$ \\
\hline L47 & ves. lava & Mag & No analysis & No analysis & $0 \%$ & 24 & 77 & $9.68 \cdot 10^{-3}$ & $24.0 \%$ \\
\hline L48 & ves. lava & Mag & $1.0 \%$ & $1.2 \%$ & $0 \%$ & 17 & 89 & $6.33 \cdot 10^{-3}$ & $20.5 \%$ \\
\hline L81 & dense lava & Mag & $3.2 \%$ & $4.0 \%$ & $27 \%$ & 40 & 84 & $8.55 \cdot 10^{-3}$ & $8.0 \%$ \\
\hline L93 & dyke & Mag & $0.2 \%$ & $0.4 \%$ & $2 \%$ & 4 & 28 & $1.08 \cdot 10^{-2}$ & $24.0 \%$ \\
\hline L116 & dense lava & Ti-Mag, Ilm & $1.1 \%$ & $1.2 \%$ & $12 \%$ & 29 & 44 & $3.99 \cdot 10^{-3}$ & $11.3 \%$ \\
\hline L117 & dense lava & Ti-Mag, Ilm & $1.7 \%$ & $1.9 \%$ & $10 \%$ & 21 & 66 & $2.83 \cdot 10^{-3}$ & $5.1 \%$ \\
\hline L118 & dense lava & see L117 & No analysis & No analysis & $10 \%$ & 22 & 46 & $3.14 \cdot 10^{-3}$ & $4.9 \%$ \\
\hline
\end{tabular}

Note. The columns rock type and major indicate, for each sample, the type of rock and of dominant metallic minerals, respectively. Other minor metallic minerals are sometimes sporadically observed in the matrix. The columns $v_{\min }$ and $v_{\max }$ give the estimated volume fraction of metallic grains, using lowand high-brightness thresholds for the image analysis, respectively, except for samples L82 and L41 where the two values correspond to quantification on two different images. The smectite volume fraction is given in the next column. The estimated maximum phase angle (MPA) is shown in the next two columns. Since the MPA depends on the fluid conductivity, the two extreme values are given. The MPA are retrieved at frequencies below $1 \mathrm{kHz}$, except for samples L19 and L81 where they are retrieved at frequencies below $10 \mathrm{kHz}$. The last two columns give the in-phase conductivity at $1 \mathrm{~Hz}$ and $0.13 \mathrm{~S} / \mathrm{m}$ and the porosity. For five samples (L24b, L12b, L45, L46b, and L118), the type of metallic mineral was not directly analyzed but inferred from the composition of neighboring samples coming from the same lithological layer and having very similar X-ray diffraction patterns. In addition, three of these samples (L24b, L12b, and L46b) come from the same original core but were prepared in an orthogonal direction as their analog (L24a, L12a, and L46a); therefore, the mineral quantification of their analog sample is assumed to be a relevant estimate. $\mathrm{Pyr}=$ pyrite $=\mathrm{FeS}_{2} ;$ Pyrrh $=$ pyrrhotite $=\mathrm{Fe}_{0.8-1} \mathrm{~S} ;$ Troil $=$ troilite $=\mathrm{FeS} ; \mathrm{Hayc}=$ haycockite $=\mathrm{Cu}_{4} \mathrm{Fe}_{5} \mathrm{~S}_{8}$; Rut $=$ rutile $=\mathrm{TiO}_{2} ; \mathrm{Mag}=$ magnetite $=\mathrm{FeO}, \mathrm{Fe}_{3} \mathrm{O}_{4}$; Ti-Mag $=$ titanomagnetite $=\mathrm{Fe}_{2-3} \mathrm{Ti}_{0-1} \mathrm{O}_{4} ; \mathrm{Ilm}=$ ilmenite $=\mathrm{FeTiO}_{3}$. Ves. lava $=$ vesicular lava; bas. breccia $=$ basaltic breccia. SEM = scanning electron microscope; EPMA = Electron Probe Micro-Analysis. 

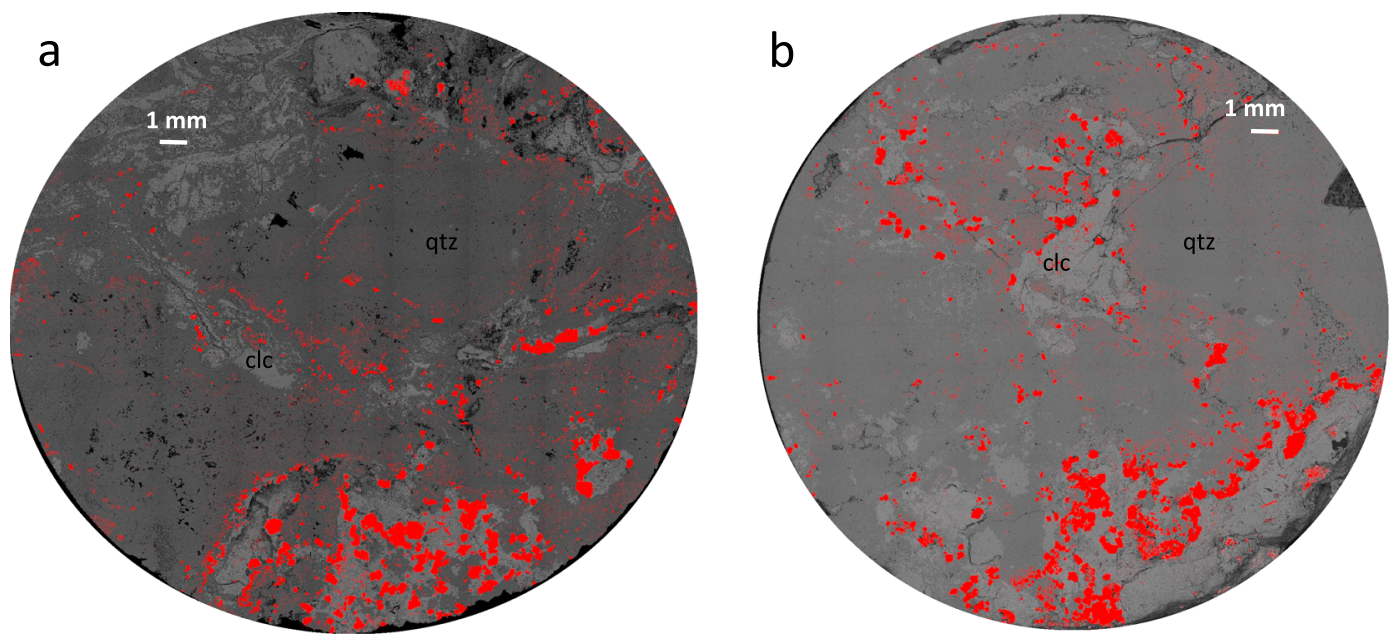

Figure 1. SEM pictures of sample L41: (a) polished thin section of one end of the cylindrical plug and (b) cross-sectional area in the middle of the cylindrical plug, which was transversally cut after all measurements were completed; the resulting half-plug was polished. These two different SEM images are used for quantification and allow to assess the extent of the three-dimensional heterogeneity. The sulfide minerals are emphasized in red, after image processing by the software ImageJ. The resulting surface fractions are $4.3 \%$ and $5.3 \%$, respectively. SEM $=$ scanning electron microscope.

to the average CEC of smectite in these samples, fitted to the linear trend CEC $=f\left(\mathrm{Smec}_{\mathrm{wt} \% \text { ) }}\right.$ (Lévy et al., 2018).

\subsection{Electrical Impedance}

The electrical impedance was measured with a Solartron 1260 impedance-meter and a four-electrode setup, following Vinegar and Waxman (1984), where the voltage and current electrodes are separated. The sample holder is presented in Figure S1 in the supporting information. An alternating current in the frequency range $10 \mathrm{mHz}$ to $1 \mathrm{MHz}$ was injected between Nickel electrodes (good resistance to corrosion) and the resulting sinusoidal voltage was measured between nonpolarizable $\mathrm{Ag} / \mathrm{AgCl}$ electrodes.

For a sinusoidal voltage $U(t)=U_{0} \sin \left(\omega t+\theta_{U}\right)$ and current $I(t)=I_{0} \sin \left(\omega t+\theta_{I}\right)$, the electrical impedance $Z$ is given by $U(t)=Z I(t)$, where $\omega$ is the angular frequency in radians per second, $t$ is the time in seconds, and $\left(U_{0}, \theta_{U}\right)$ and $\left(I_{0}, \theta_{I}\right)$ are the amplitudes and phase angles of the sinusoidal voltage and current, respectively. Due to the alternating character of the electrical signal, it is convenient to write $I, U$, and $Z$ as complex numbers (equation (2); Agarwal \& Lang, 2005; Barsoukov \& Macdonald, 2018; Sumner, 1976).

$$
Z(\omega)=\frac{U_{0} e^{i\left(\omega t+\theta_{U}\right)}}{I_{0} e^{i\left(\omega t+\theta_{I}\right)}}=|Z(\omega)| e^{i \theta(\omega)}
$$

where $Z, U$, and $I$ are in $\Omega, V$, and $A$, respectively, $|Z(\omega)|$ in $\Omega$ is the modulus of the impedance and $\theta(\omega)=$ $\theta_{I}-\theta_{U}$ in radians is the (frequency-dependent) phase angle of the impedance, as shown in Figure 2. Most of the time, the phase angle of the impedance is negative, corresponding to a delay of the voltage relative to the current.

Impedance measurements of the electrical cell filled with water (no rock sample) at different fluid conductivities, where no polarization is expected, is shown in Appendix A. The resulting phase angle varies between 1.5 and $-1 \mathrm{mrad}$ in the range $0.1-1000 \mathrm{~Hz}$. These values, obtained over a wide range of fluid conductivities are higher than the value of $\pm 0.3 \mathrm{mrad}$ reported (only at $0.0085 \mathrm{~S} / \mathrm{m}$ ) by Lesmes and Frye (2001), using a similar setup and sample holder, in the same frequency range. Our uncertainty is also significantly higher than the value of \pm 0.1 mrad obtained with the setup presented by Zimmermann et al. (2008), most suitable for investigation of low phase angles. However, our measurement setup presents the considerable advantage of being easy and quick to use, which allowed us to run 10 to 15 measurements per sample, including redundant measurements. Moreover, the large phase angles considered here, mostly in the range 20-200 mrad (see Figure 2), the reproducibility of our measurements over time (see Figure S3 in the supporting information), 

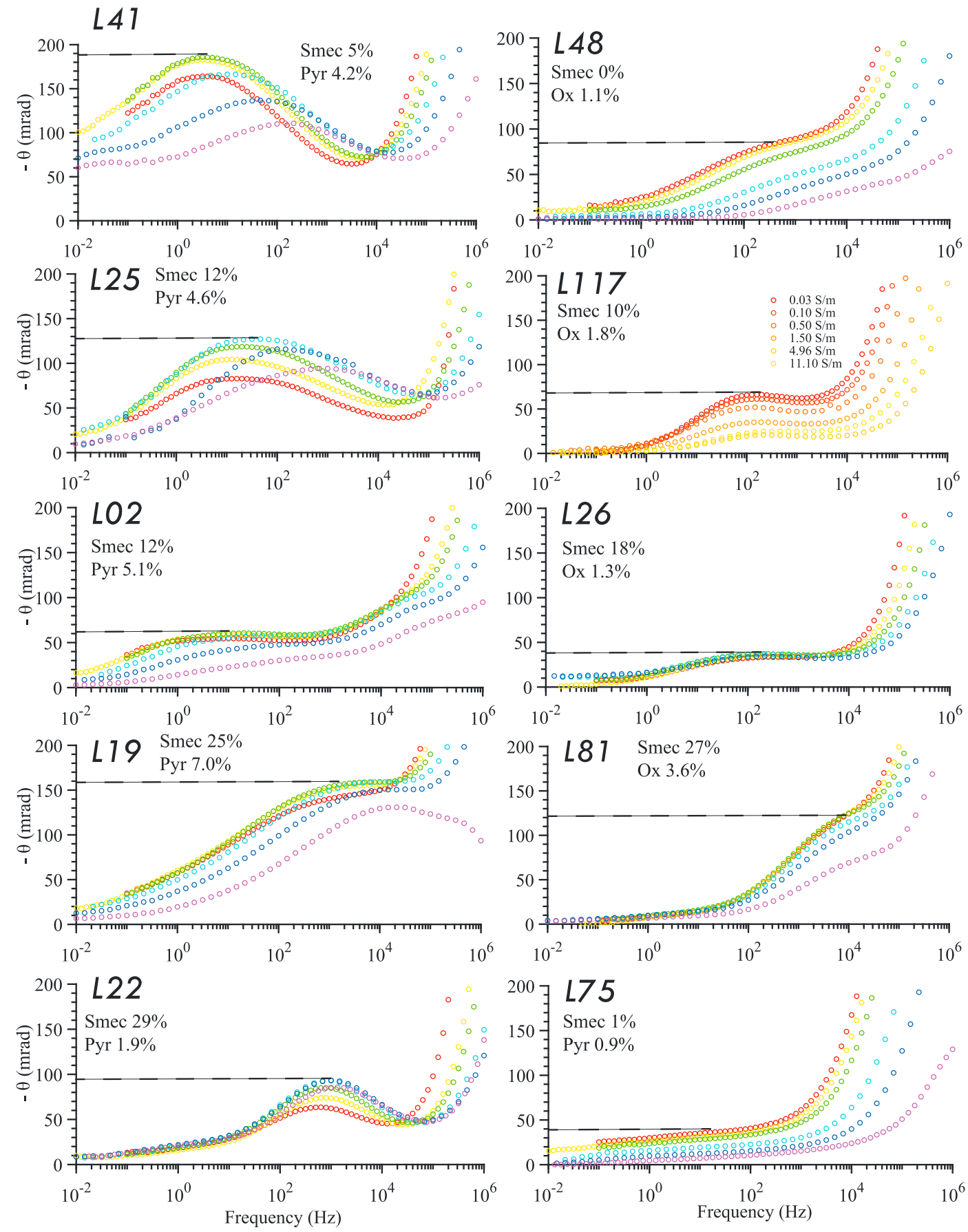

$$
\circ 0.02 \mathrm{~S} / \mathrm{m}
$$

$0.05 \mathrm{~S} / \mathrm{m}$

$\circ 0.13 \mathrm{~S} / \mathrm{m}$

$\circ 0.50 \mathrm{~S} / \mathrm{m}$

$01.51 \mathrm{~S} / \mathrm{m}$

$05.33 \mathrm{~S} / \mathrm{m}$

Figure 2. Phase spectra (negative phase angle $\theta$ versus alternating current frequency) from laboratory measurements of frequency domain electrical impedance for 10 samples, at different fluid conductivities (see color scale at the bottom, except for sample L117 that has separate color scale). The inferred maximum phase angle is indicated by the horizontal line. The respective smectite (Smec) and pyrite (Pyr) volume fractions are also indicated. 
and the consistency of the trends observed between different samples, did not require further improvements in the measurement accuracy.

\section{Results}

An increase of the phase angle at frequency higher than 1-10 kHz is observed for all samples (Figure 2). This corresponds to high-frequency (HF) polarization phenomena, mostly attributed to polarization at the electrodes (Abdulsamad et al., 2016; Macdonald, 2000), although part of the observed polarization effect may also come from the so-called Maxwell-Wagner polarization (Chelidze \& Gueguen, 1999). Because of these important effects, phase angle peaks due to polarization in the rock can only be observed at low frequency $\left(f \leq 10^{4} \mathrm{~Hz}\right.$ ). Polarization effects described in the rest of the study refer to low-frequency effects, unless the term HF polarization is used.

Since one objective of our study is to provide interpretations to IP parameters obtained in the field, simple parameters are required. We consider the MPA to be the simplest parameter, which can describe the amplitude of polarization in a comparable manner for all samples. It can be obtained directly from any phase spectrum and can also be inverted from field time domain IP measurements (Fiandaca et al., 2018; Madsen et al., 2017). We calculate the MPA, based on the phase angle value at the summit of spectral peaks (Figure 2), if a clear peak is observed in the phase spectrum, or the average phase angle of a linear/flat section when that is observed (e.g., L75). For samples showing two maxima (e.g., L02 at 1 and 105 Hz), we take the MPA at the lower frequency. Moreover, the bulk real conductivity at $1 \mathrm{~Hz}, \sigma_{1 \mathrm{~Hz}}$, is used to represent the real part of the conductivity (equation (3)). The value at $1 \mathrm{~Hz}$ is chosen as it is most relevant for field applications, but the bulk real conductivity is considered almost frequency independent (see, e.g., Maurya et al., 2018).

$$
\sigma(\omega)=\frac{Z^{\prime}(\omega)}{|Z(\omega)|^{2}} \frac{L}{A}
$$

where $\sigma$ and $Z^{\prime}$ are the real part of the bulk electrical conductivity and impedance, respectively. $L$ and $A$ are the length and cross-sectional area of the plug. $\sigma_{1 \mathrm{~Hz}}$ is comparable to the conductivity measured in the field, often in the range $0.1-100 \mathrm{~Hz}$.

Together, the MPA and $\sigma_{1 \mathrm{~Hz}}$ provide a fair description of the complex resistivity spectra, which we use to relate IP response to mineralogy in our study. The peak frequency at which the MPA is reached, is, however, missing in this description. Since it is a more complicated and ambiguous parameter to calculate, both in field and in time domain IP studies, we do not analyze it quantitatively here (Fiandaca et al., 2018; Maurya et al., 2018).

Impedance spectra were also fitted with an electrical equivalent circuit model, based on the empirical Cole-Cole models (Cole \& Cole, 1941; Davidson \& Cole, 1951; Hallof \& Klein, 1983; Havriliak \& Negami, 1966; Macnae, 2015). This approach was not appropriate for analyzing the impedance spectra of our natural volcanic samples. (Florsch et al., 2012; Ghorbani et al., 2007). Therefore, Cole-Cole fits are not used in the rest of the paper but are, instead, presented and discussed in supporting information S2.

\subsection{Identifying the Presence of Pyrite}

The MPA is in the range 4-89 mrad for samples with iron oxides and in the range 7-186 mrad for samples with pyrite. Large variability with fluid conductivity is observed, with up to $70 \%$ decrease when the fluid conductivity increases from 0.02 to $5 \mathrm{~S} / \mathrm{m}$. Among the 30 samples analyzed, only 3 samples, L31, L119, and L123, contain $\leq 0.5 \%$ of metallic particles. These samples have a high smectite volume $(\geq 30 \%)$ and the lowest MPA ( $\leq 20 \mathrm{mrad})$.

Samples with high MPA ( $\geq 30 \mathrm{mrad}$ ) contain sulfides or iron oxides in significant amounts $(\geq 1 \%)$. Most samples with pyrite have $\sigma_{1 \mathrm{~Hz}}$ higher than $10^{-2} \mathrm{~S} / \mathrm{m}$ (Figure 3). More accurately, the presence of pyrite is likely if the couple MPA- $\sigma_{1 \mathrm{~Hz}}$ plots to the right of the division line shown in Figure 3 . The different geological matrices in which titanomagnetite and pyrite are embedded can explain this discrimination.

Iron oxides, which usually form during primary crystallization of magma (Haggerty, 1976), are found in fresh, crystalline samples, which have undergone limited hydrothermal alteration (samples L48, L26, L81, and L117 in Figure 4 and sample L48 in Figure 5). Moreover, the spatial distribution of titanomagnetite is homogeneous (samples L48, L26, L81, and L117 in Figure 4). 


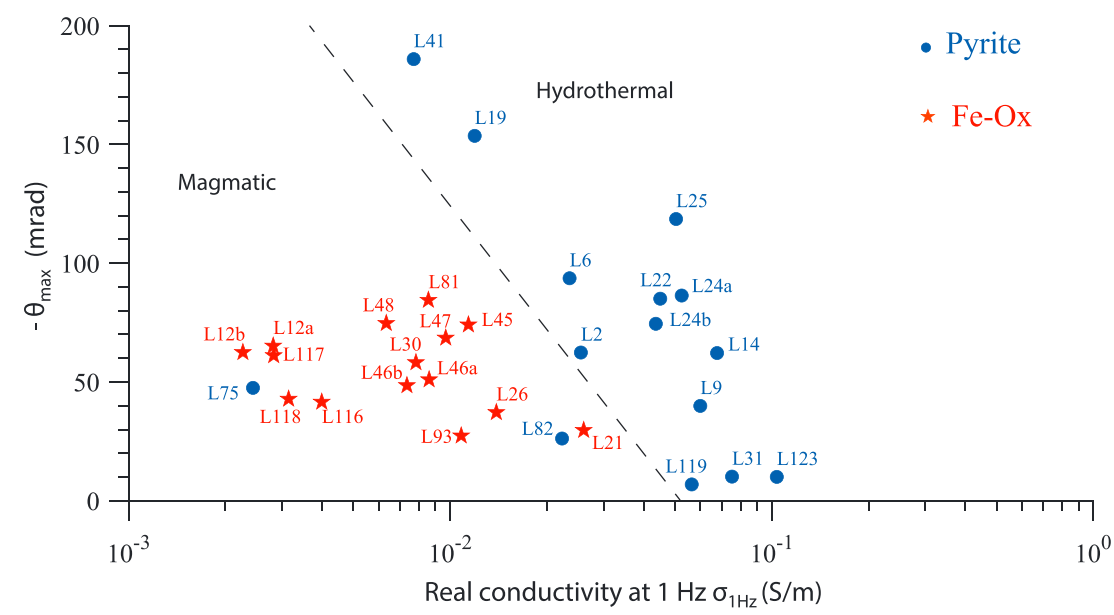

Figure 3. Maximum phase angle versus $\sigma_{1 \mathrm{~Hz}}$ for all samples, at pore fluid conductivity of $0.13 \mathrm{~S} / \mathrm{m}$. The black line separates hydrothermal and magmatic metallic mineralization.

The cocrystallization (in equilibrium; ; Bacon \& Hirschmann, 1988) of ilmenite and titanomagnetite (at 80\% ilmenite and 70\% ulvospinel, respectively) in samples L30 and L46a allows calculation of the crystallization temperatures and oxidation-reduction conditions, by geothermometry and oxygen barometry. Calculated temperatures are consistent with the formation of basalt: $T=1140$ and $1100 \pm 30^{\circ} \mathrm{C}$, respectively. Corresponding oxygen partial pressures are close to the quartz-fayalite-magnetite buffer $\left(f_{\mathrm{O}_{2}}=-8.87\right.$ and -9.39 , respectively; Ghiorso \& Sack, 1991). These calculations confirm that iron oxides are magmatic minerals and that the environment of crystallization is in a relatively reduced state, according to classical calibrations (Powell \& Powell, 1977).
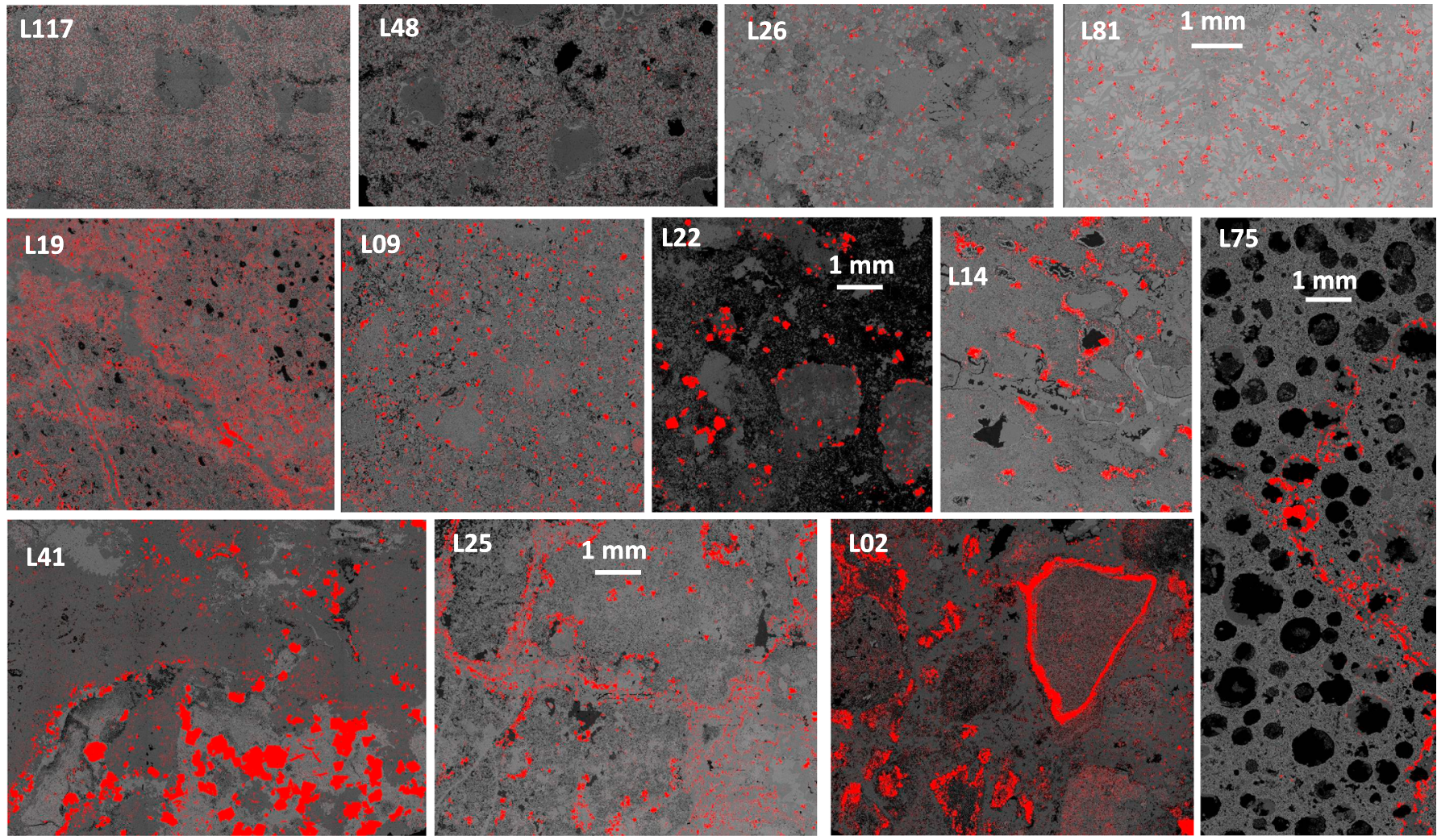

Figure 4. Scanning electron microscope images for 12 samples (all at the same scale). Red color indicates the presence of metallic particles. The top four samples (L117, L48, L26, and L81) contain iron oxides and the others pyrite. 

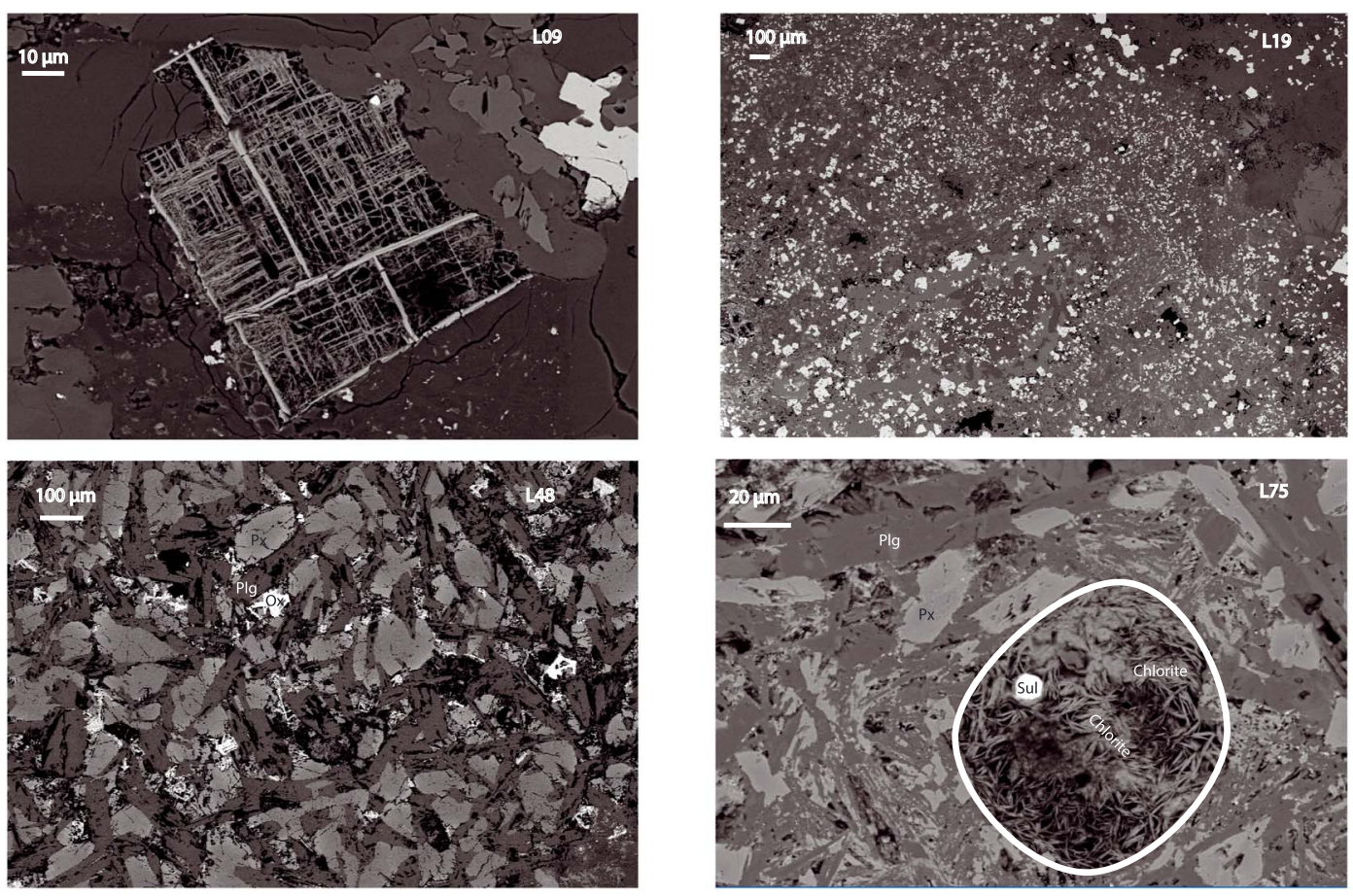

Figure 5. Scanning electron microscope pictures of polished thin section from samples L09, L19, L48, and L75. In sample L09, a former iron oxide (ilmenite), exsolved by hydrothermal circulation, is shown. In sample L19, small and abundant pyrite minerals from hydrothermal alteration are observed. In samples L48 and L75, intact primary pyroxenes (light gray, "px") and plagioclases (dark gray, "plg") are seen, showing that the surrounding matrix is well crystallized and fresh. Intact primary iron oxides (white, "ox") are also seen in L48. For sample L75, the vesicle outlined at the center of the image, is filled with chlorite. One sulfide crystal ("Sul," haycockite in this case) is also observed in the vesicle.

Sulfides (mostly pyrite) are found in hydrothermally altered samples (samples L09, L19, L14, L22, L41, L25, and L02 in Figure 4). In these samples, large smectite volumes are usually also present (Table 1), which causes a higher real conductivity (Lévy et al., 2018). In these altered samples, iron oxides have been dissolved, as illustrated in Figure 5 for sample L09. Sulfides are usually concentrated along fractures and vesicles or clasts rims (see, in particular, samples L19, L22, L14, L25, and L02 in Figure 4). In samples L41 and L75, sulfides are localized in one area of the thin section (see Figure 1 for L41).

Figure 4 demonstrates the complexity of hydrothermally altered samples. Two types of grain size (of metallic particles) distributions are shown: (i) frequency of each bin of particle sizes in terms of number of particles (classical distribution) and (ii) a distribution calculated as the surface fraction covered by each bin. Figure 4 shows that most of the metallic particles are small (cross-sectional area in the range 10-100 $\mu \mathrm{m}$ for all samples), but the few big particles (cross-sectional area greater than $10^{4} \mu \mathrm{m}$ ) can represent an important, or dominant, fraction of the total area covered by metallic particles. The total area covered by metallic particles, divided by the total area of the thin section, is here our measure of the volume percentage of metallic particles. The second type of distribution shows different patterns for each sample. These patterns seem to have an influence on the phase spectrum (Figure 2). Indeed, sample L02 contains metallic particles whose section area distribution has two small maxima, at $10^{2}$ and $10^{5} \mu \mathrm{m}^{2}$, which are reflected in the two small polarization peaks observed at 1 and $10^{4}-10^{5} \mathrm{~Hz}$ in Figure 2. Sample L19 contains metallic particle with one clear maximum section area at $10^{3} \mu \mathrm{m}^{2}$, which is reflected by one strong polarization peak at $10^{4} \mathrm{~Hz}$. Finally, sample L41 contains metallic particles with a maximum section area at $10^{5} \mu \mathrm{m}^{2}$, which is reflected in the polarization peak at $1 \mathrm{~Hz}$. The connectivity of small pyrite grains, for example in sample L25, may also explain low peak frequencies. However, this connectivity cannot be quantified from SEM image analysis.

Two samples with sulfides, L75 and L82, lie left of the division line in Figure 3. Sample L75 contains about $0.8 \%$ sulfide but the low level of alteration indicates that sulfides may have formed during magmatic 
crystallization rather than hydrothermal alteration (Figure 5). Indeed, an intact crystalline matrix is observed in this sample and the chlorite in-filling found with sulfides in closed vesicles tends to indicate late-magmatic crystallization of chlorite rather than during hydrothermal alteration (Berger et al., 2018; Meunier et al., 2012; Merle et al., 2005). The same was observed for sample L82, but in-fillings were rather of mixed-layer smectite/chlorite nature (e.g., corrensite). This type of sulfide mineralization is not detectable with the approach suggested here, but is of little interest for geothermal industry.

The discrimination between iron oxides (mostly titanomagnetite) and sulfides (mostly pyrite) shown here for a fluid conductivity of $0.13 \mathrm{~S} / \mathrm{m}$ is valid at all fluid conductivities up to $0.5 \mathrm{~S} / \mathrm{m}$. Beyond $1.5 \mathrm{~S} / \mathrm{m}$, samples with titanomagnetite can be as conductive as samples with pyrite, if not more conductive, for samples with no smectite but low formation factor (Figure S11 in the supporting information). In low-salinity geothermal fields, such as Krafla (fluid conductivity $0.07 \mathrm{~S} / \mathrm{m}$ at $25^{\circ} \mathrm{C}$ ), fluid conductivities higher than $0.5 \mathrm{~S} / \mathrm{m}$ are unlikely. Indeed, even if the temperature reached $250^{\circ} \mathrm{C}$ at the depths investigated, the in situ fluid conductivity would be $0.39 \mathrm{~S} / \mathrm{m}$, using a conductivity increase of $2 \% /{ }^{\circ} \mathrm{C}$ (Arps, 1953; Hayashi, 2004). However, in saline geothermal systems, such as Reykjanes in Southwest Iceland, the discrimination may not be feasible. Finally, in contexts where pyrite is not formed by hydrothermal processes, the discrimination method suggested here may not be relevant.

\subsection{Estimating the Volume of Pyrite}

The volume fraction of iron oxides is in the range 1-2\% in samples where iron oxides are the major metallic minerals and less in other samples. The volume fraction of sulfides ranges from $\leq 0.1 \%$ to $7 \%$ in all samples. The volume fraction of smectite is in the range $0-30 \%$ (Table 1 ).

We observe that the MPA generally increases with the volume fraction of pyrite and titanomagnetite in a linear manner (Figure 7), with a slope of $22 \mathrm{mrad} / \mathrm{vol} . \%$ of metallic particles (or to $2.2 \mathrm{rad}$ when the $x$ axis is set to the interval $0-1$ instead of percentages). Similar trends are observed at different pore fluid conductivities (Figure S12 in the supporting information). The linear relationship between the MPA and the volume of metallic particles may be qualitatively interpreted as an increase of the time needed for the maximum voltage to be reached, when more metallic surface is exposed to the fluid, due to more intense local displacement currents associated to longer redistribution of charges before an equilibrium is reached.

However, many samples deviate from the main trend in Figure 7. We suggest that most of the deviation is caused by the influence of interfoliar conductivity through connected smectite particles, which prevents polarization to occur (Lévy et al., 2018). Indeed, we observe a decrease of the MPA with increasing smectite content, for a given pyrite content (Figure 8a). For samples with hydrothermal pyrite and smectite, a general decreasing trend is observed between MPA and $\sigma_{1 \mathrm{~Hz}}$ when considering all samples together (Figure 8a). For samples containing magmatic iron oxides, a linear trend is observed for each sample separately (Figure 8b), while their MPA are all in a narrow range (Figure 7). This indicates that varying electrolyte concentration (salinity) causes larger variations of the MPA than the different pore structures and iron oxides types and content in these magmatic unaltered samples, which is consistent with the fact that all basaltic rocks contain primarily $1-2 \%$ of iron oxides in volume. In hydrothermal samples, the MPA varies much more, due to more variable volumes of pyrite, and is also affected both by the counter influence of smectite and electrolyte concentration. We also observe that, for hydrothermal samples, the MPA reaches a maximum at a certain $\sigma_{1 \mathrm{~Hz}}$ (Figure 8a). The fluid conductivity corresponding to this maximum varies from 0.13 to $1.5 \mathrm{~S} / \mathrm{m}$, depending on the sample.

As a consequence, in volcanic environments, the MPA needs to be considered together with the bulk real conductivity in order to (i) determine if the IP response corresponds to pyrite or iron oxides and (ii) estimate the pyrite content.

\section{Discussion}

\subsection{Complexity of Natural Samples}

We mentioned earlier the difficulty of fitting the impedance spectra with Cole-Cole models. We suggest this relates to the complexity of natural samples, illustrated in particular by Figure 4.

First, higher peak frequencies are observed in our samples than in studies on synthetic samples (Revil et al., 2017; Wong, 1979). This makes the discrimination between rock and apparatus polarization (as well as other 

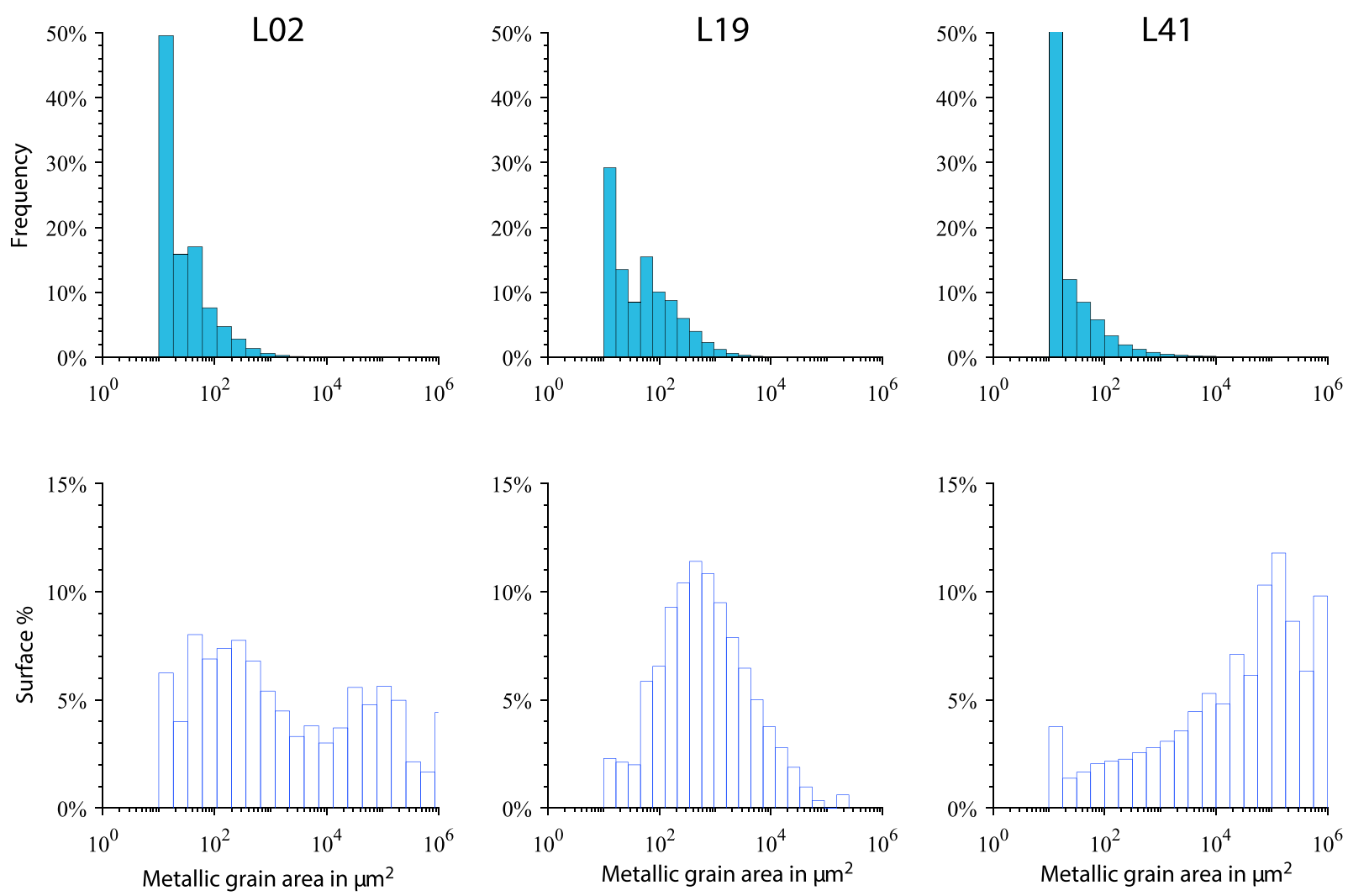

Figure 6. Distribution of metallic grain areas of sulfide minerals in samples L19, L02, and L41. The upper panels show the frequency of each area bin, while the lower panels show the surface covered by each bin, divided by the total surface covered by metallic particles. All the bins corresponding to areas greater than $10^{4} \mu \mathrm{m}^{2}$ contain only one particle; they are thus invisible in the upper panels. The bin corresponding to the smallest grain areas $\left(10 \mu \mathrm{m}^{2}\right)$ contains about 70,000 particles for each sample.

HF effect) more difficult. This is probably due to the natural abundance of very small pyrite and iron oxides minerals in volcanic environments (see, e.g., sample L19 in Figures 5 and 6), unlike in massive sulfide ore deposits or synthetic samples with controlled grain size. Indeed, a decreasing grain size of metallic particle causes higher polarization frequency (Wong, 1979).

Second, the asymmetry of low-frequency polarization peaks, or even the presence of two clear distinct relaxation peaks (e.g., small secondary peak for L41 at high fluid conductivity around $0.1 \mathrm{~Hz}$ and two peaks

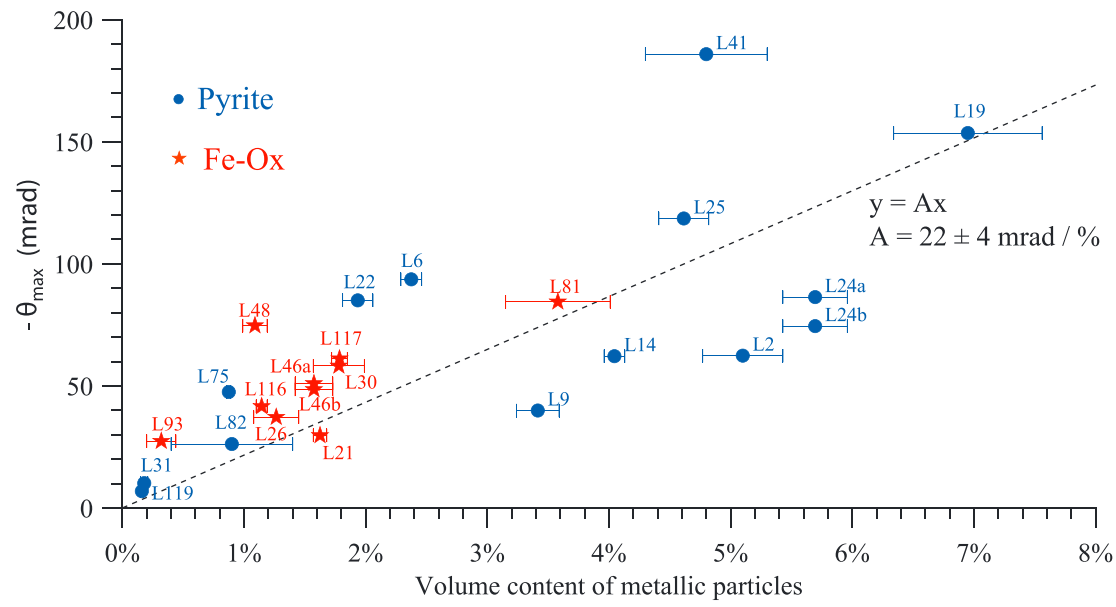

Figure 7. Maximum phase angle versus volume fraction of metallic particles, at pore fluid conductivity of $0.13 \mathrm{~S} / \mathrm{m}$. The black line corresponds to a linear fit constrained to pass through $(0,0)$. The slope of the line is $22 \pm 4 \mathrm{mrad} / \mathrm{vol} . \%$. 

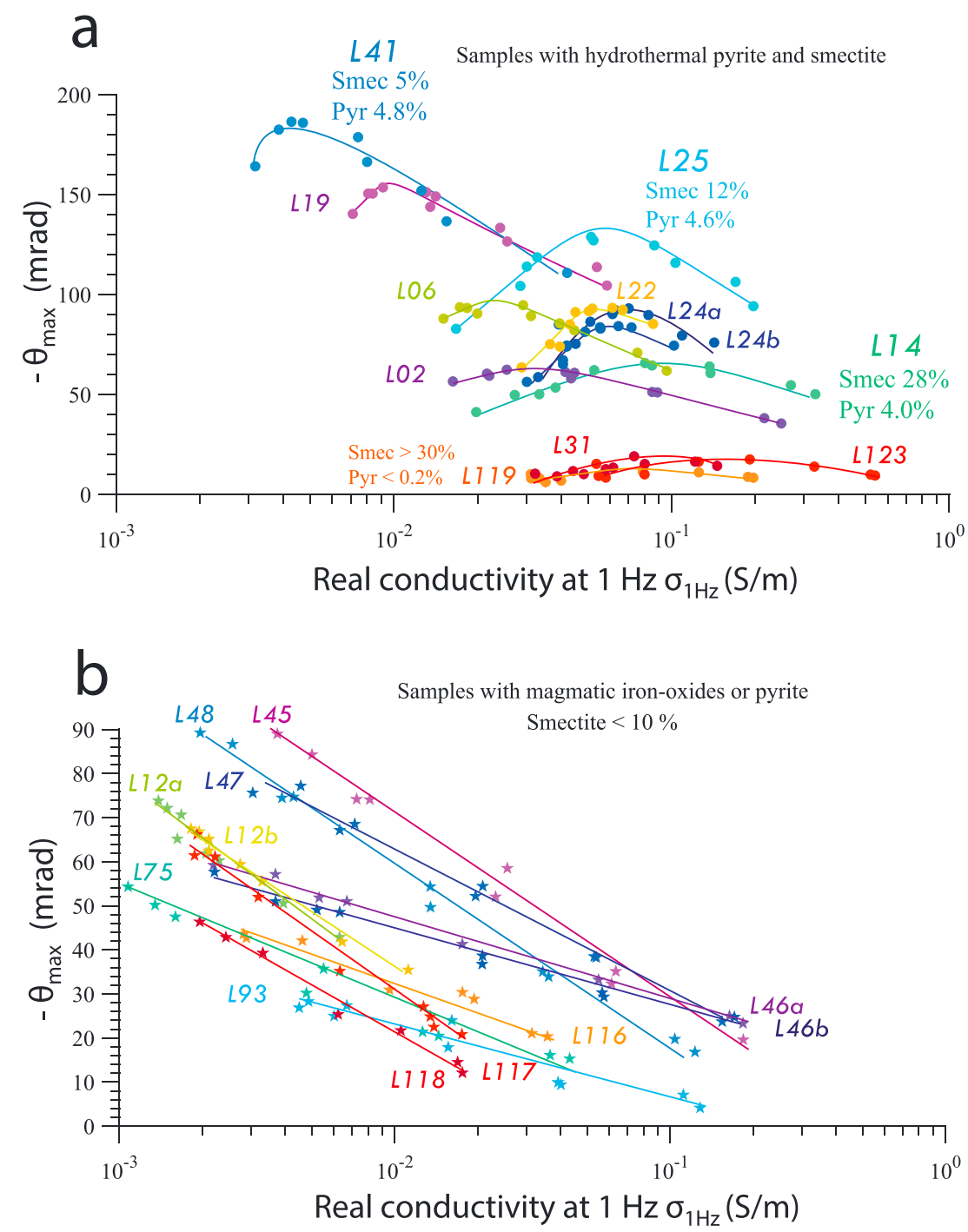

Figure 8. Maximum phase angle versus $\sigma_{1 \mathrm{~Hz}}$ for (a) samples with hydrothermal pyrite and smectite; (b) samples with magmatic iron oxides, besides sample L75, which contains sulfides (most likely from magmatic origin). One color corresponds to one sample (curves/lines show general trends). In (a), samples L41, L25, and L14 have similar pyrite volumes but decreasing smectite volumes.

around 1 and $10^{5} \mathrm{~Hz}$ for L02 in Figure 2) can be explained by the large variability of grain sizes and connectivity between metallic grains, which exists in natural samples. Indeed, samples L41 and L02 have a complex distribution of grain sizes (Figures 4 and 6). On the other hand, sample L19 has a simple distribution of grain sizes (Figure 6) and can be correctly fitted with a simple Cole-Cole model (Figure S5 in the supporting information).

Less bias is introduced when calculating the MPA directly from the phase spectra than when inverting the chargeability by fitting impedance spectra with Cole-Cole models. The MPA can be slightly overestimated for samples having a maximum polarization at HF (L09, L19, L81, and L75; see Figure 2), but this does not cause deviation to the quantitative trend in Figure 7, since these samples are on the trend or below. Therefore, the MPA seems appropriate to describe the amplitude of polarization in natural samples. The MPA together with the bulk real conductivity at $1 \mathrm{~Hz}$ provides a convenient description of the complex electrical properties of natural samples.

The multiplicity (L02), flatness (L75), and asymmetry (L41) of polarization peaks make it difficult to determine a peak frequency or relaxation time. A qualitative comparison of the peak frequency to the metallic 
grain size distribution was carried out, showing that the peak frequency seems to be controlled by the metallic particles with the largest section areas, although these particles only represent a negligible number of particles, compared to the total number of metallic particles. In order to analyze further the influence of metallic grain size on the peak frequency, a further study could be carried out to obtain a distribution of relaxation times (RTD), for example, by Debye decomposition (Florsch et al., 2014; Nordsiek \& Weller, 2008; Weigand \& Kemna, 2016). Different kernel functions could be tested for the decomposition (Debye, Warburg, and Cole-Cole) and the resulting total chargeability could be compared to the MPA and volume content of metallic particles, while the relaxation time distribution could be compared to the grain size distribution.

We also mentioned the difficulty of quantifying the pyrite volume, due to heterogeneity inside some samples. Despite this natural heterogeneity, we observe simple trends between the MPA and the bulk mineral content. These trends are relevant for field interpretations where the averaging of large volumes includes heterogeneous structures.

Several models predict a relationship between the chargeability, or the percentage frequency effect (PFE), and the volume percent of metallic particles. In all models, this relationship corresponds more or less to a slope of 9/2, which is verified on synthetic samples (Abdulsamad et al., 2017; Revil et al., 2017; Wong, 1979; Wait, 1983). The PFE, which is the relative variation of the real conductivity between two given frequencies, and thus an approximation of the chargeability, is supposed to be proportional to the phase angle at the geometrical mean frequency and is therefore closely related to the MPA (e.g., Revil et al., 2017). We do obtain a consistent slope of $240 \pm 10 \mathrm{mrad}$ between the MPA and the PFE at all salinities (see Figure S7 in the supporting information). However, this slope corresponds to a coefficient of $9.0 \pm 1.5$ between the PFE and the volume content of metallic particles, according to the fit in Figure 7. Therefore, our data set does not follow the trend between the PFE and the volume content of metallic particles predicted by the above-mentioned models and verified on synthetic samples ( 9 in our case versus $9 / 2$ in models). Interestingly, the slope obtained in Figure 7 is very close to the value 9/4 suggested between the MPA and the volume content of metallic particles in the model by Revil et al. (2015).

\subsection{Dependence of MPA Upon Bulk Electrical Conductivity}

Curves in Figure 8b and the decreasing part of curves in Figure 8a, showing a decrease of MPA with increasing fluid conductivity, are consistent with other laboratory observations (e.g., Joseph et al., 2015; Kruschwitz, 2007; Lesmes \& Frye, 2001) and also predictions of membrane polarization phenomena by numerical modeling (Bücker \& Hördt, 2013; Hördt et al., 2016). Abdulsamad et al. (2017) suggest that the chargeability (or MPA) is independent of the electrolyte concentration, based on their observations on synthetic samples composed of sandstone with metallic particles. However, similar behavior to ours cannot be ruled out based on their Figure 4 only. Indeed, the curves corresponding to samples saturated with $\mathrm{NaCl}$ hint toward a similar behavior to ours, which could be confirmed by measurements on samples with larger volume content of metallic particles, saturated with a denser variation of $\mathrm{NaCl}$ concentrations. The $x$ axis in Figure 8 shows the bulk real conductivity and not the fluid conductivity, but for a given sample the bulk conductivity increases monotonously with the fluid conductivity (Waxman \& Smits, 1968), so that the shape of the curves is similar. The bulk conductivity is preferred because it includes a possible contribution from smectite minerals, which varies between samples. Smectite is more conductive than other clay minerals because cation exchange can occur inside the smectite crystals, between the clay tablets, and not only at the edges (Lévy et al., 2018). Therefore, the electrical current can flow through the smectite crystal, which may bypass polarization at the interface between fluid and smectite and cause a decrease in overall polarization, whereas other clay minerals would increase the overall polarization (Weller et al., 2013). Studying in more detail the conductivity within the clay tablets and polarization at the interface between fluid and connected smectite particles in volcanic rocks could improve, in the future, our understanding of the counter-effect of smectite on IP observed here.

A group of samples also reaches a maximum MPA for a certain window of fluid conductivity (Figure 8a). These samples contain pyrite and various amounts of smectite; samples with higher smectite volume seem to reach their maximum MPA at higher fluid conductivity. A similar behavior was observed for sandstones samples (Kruschwitz, 2007). This behavior is also predicted by numerical modeling of membrane polarization, in a system consisting of a sequence of narrow and wide pores, where the membrane effect is caused by different mobility of the ion species in the two pore types (Hördt et al., 2016). By analogy with the model developed by Hördt et al. (2016), we suggest that the presence of smectite with connected interfoliar spaces 
creates a conduction network similar to a system of narrow and wide pores. In the range of fluid conductivity where the increase of MPA is observed, electrical conduction within connected interfoliar spaces of smectite and along the electrical double layer dominate the overall bulk conductivity. When salinity increases, the electrical double layer (e.g., at the outer surface of smectite minerals) becomes smaller. This may cause a higher mobility contrast between "regular" porosity and interfoliar spaces and thus higher membrane polarization. Interfoliar spaces would be here comparable to narrow pores in the model by Hördt et al. (2016). A possible explanation for the increasing-decreasing sequence here is that increased salinity causes an increase membrane polarization but a decrease of electrode polarization (i.e., polarization associated to metallic particles). Therefore, the overall polarization, dominated by polarization at the interface metal-electrolyte, will eventually decrease upon increasing salinity when the increase of membrane polarization becomes negligible. The model by Hördt et al. (2016) also predicts that smaller pore radii are associated to higher peak salinities for the MPA. This is consistent with the qualitative observation that the peak salinity of the MPA increases with the smectite content in Figure 8.

\section{Conclusions}

The amplitude of the frequency domain IP response of volcanic rocks, represented in this study by the MPA, depends in a complex manner on amounts of pyrite, iron oxides, and smectite as well as pore fluid conductivity. Natural volcanic rocks are more complex than theoretical models and synthetic samples. Despite this complexity, we observe clear trends that can constrain the location and volume of pyrite mineralization in volcanic environments, by considering together MPA and bulk resistivity without an a priori model. A MPA higher than $30 \mathrm{mrad}$ in volcanic rocks corresponds to either the presence of pyrite or titanomagnetite, but a high bulk electrical conductivity or a MPA higher than 80 mrad indicates the presence of pyrite. MPA increases in general with the pyrite content. However, for a given pyrite content, the MPA decreases when the smectite content increases. This decrease is consistent with a general decrease of the MPA upon increase of bulk electrical conductivity. Adjusting numerical and analytical models to describe these observations on natural samples may be an important next step in understanding IP phenomena.

\section{Appendix}

\section{Appendix A: Impedance Response of Water-Filled Tubes}

At frequencies higher than $1 \mathrm{kHz}$, the absolute value of the phase angle of the cell filled with water increases rapidly. The increase becomes less important at higher fluid conductivity but the phase angle becomes pos-

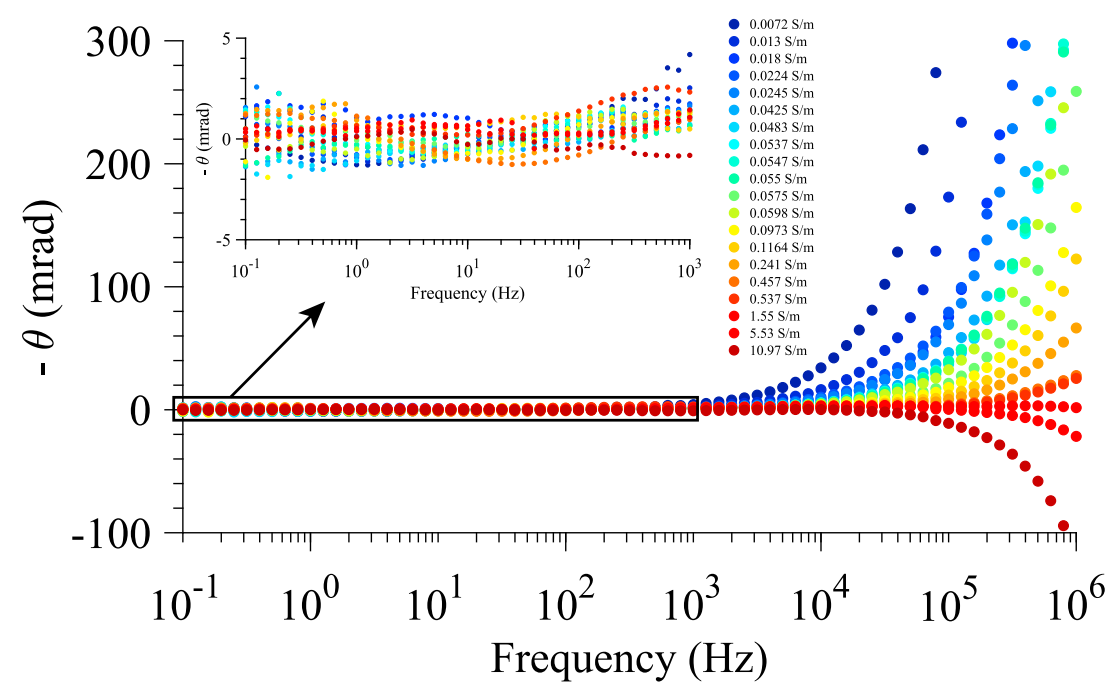

Figure A1. Phase spectra of the water-filled measuring cell in the range $100 \mathrm{mHz}$ to $1 \mathrm{MHz}$. A zoom on the low phase angle at frequency below $1 \mathrm{kHz}$ is also shown. The color scale corresponds to increasing water conductivity (from cold to warm colors). The $y$ axis represents the negative phase angle. Most of the time, the phase angle of the complex conductivity is negative, corresponding to a phase delay of the voltage relative to the current. Positive phase angles, which are below the $x=0$ line in this figure, can only be attributed to induction effects in the electrical circuit. 
itive (whereas it is negative most of the time) at fluid conductivity higher than $1.5 \mathrm{~S} / \mathrm{m}$ and the absolute value starts to increase again (Figure A1). If only dielectric absorption of water was causing the observed HF polarization, the phase angle should be only negative and much lower, considering a relative dieletric permittivity of water around $\epsilon_{r}=80$ (Abdulsamad et al., 2016). A major contribution from the measuring electrodes is likely at these frequencies, as shown by previous studies (Abdulsamad et al., 2016; Lesmes \& Frye, 2001; Volkmann \& Klitzsch, 2015).

\section{Appendix B: Chemical Analyses of Sulfides and Iron Oxides}

Figure B1 compares the chemistry of the different sulfides and iron oxides for samples, analyzed by Electron Probe Micro-Analysis. Sulfides were analyzed in samples L02, L25, L41, L19, L24a, L75, and L31. Iron oxides were analyzed in samples L21, L26, L30, L46a, L48, L93, and L117. The detailed analyses are given in large Tables S1 and S2 (supporting information).
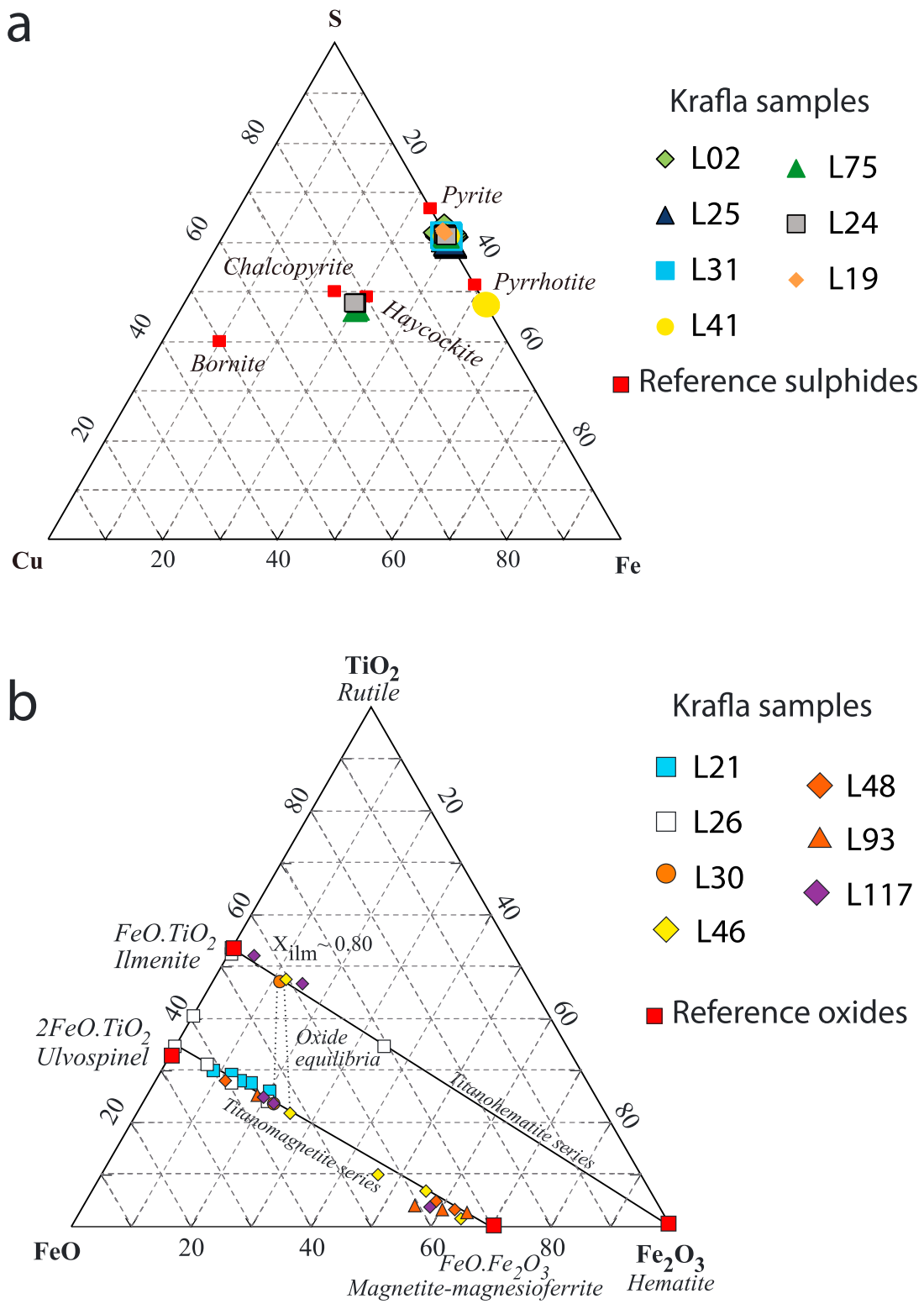

Figure B1. Sulfide and oxide composition in Krafla samples (individual analyses). (a) Cu-Fe-S ternary plot of normalized atomic proportions in sulfides. (b) $\mathrm{TiO}_{2}-\mathrm{FeO}-\mathrm{Fe}_{2} \mathrm{O}_{3}$ ternary plot of normalized weight percent of oxides in iron-titanium oxides. Titanomagnetite and titanohematite series from Lilova et al. (2012). 


\section{Acknowledgments}

The complete electrical impedance files in ascii format (Data Set S1) are available online on the sip-archiv.de collaborative platform. The phase spectra for the 30 samples at six distinct pore fluid conductivities are available as supporting information (Data Set S2). The SEM images of all analyzed samples are available to anyone upon request. The authors thank Landsvirkjun for providing the core samples and Christophe Nevado and Doriane Delmas for high-quality polished thin sections. L. L. thanks Pauline Kessouri, Svetlana Byrdina, Jean Vandemeulebrouck, Knútur Árnason, Pradip Maurya, Ólafur Flóvenz, Philippe Pezard, and Pierre Briole for fruitful discussions and André Revil for recommending the use of four-electrode setup. This research was supported by the IMAGE FP7 EC and GEMex H2020 projects (grant agreements 608553 and 727550) and by a PhD grant from Paris Sciences et Lettres to Léa Lévy. We are grateful to the Editor Stephen Parman, Nicolas Florsch, and an anonymous reviewer for the efficiency of the reviewing process and valuable feedbacks, which have very much helped improve the manuscript quality.

\section{References}

Abdulsamad, F., Florsch, N., \& Camerlynck, C. (2017). Spectral induced polarization in a sandy medium containing semiconductor materials: Experimental results and numerical modelling of the polarization mechanism. Near Surface Geophysics, 15(6), 669-683.

Abdulsamad, F., Florsch, N., Schmutz, M., \& Camerlynck, C. (2016). Assessing the high frequency behavior of non-polarizable electrodes for spectral induced polarization measurements. Journal of Applied Geophysics, 135, 449-455.

Abramoff, M. D., Magalhaes, P. J., \& Ram, S. J. (2004). Image processing with Image. Journal Biophotonics International, 11, 36-42. Agarwal, A., \& Lang, J. (2005). Foundations of analog and digital electronic circuits. Elsevier.

Arps, J. J. (1953). The effect of temperature on the density and electrical resistivity of sodium chloride solutions. Journal of Petroleum Technology, 5(10), 17-20.

Bacon, C. R., \& Hirschmann, M. M. (1988). Mg/Mn partitioning as a test for equilibrium between coexisting Fe-Ti oxides. American Mineralogist, 73, 57-61.

Barsoukov, E., \& Macdonald, J. R. (2018). Impedance spectroscopy: Theory, experiment, and applications. Hoboken, NJ: John Wiley \& Sons. Berger, G., Beaufort, D., \& Antoine, R. (2018). Clay minerals related to the late magmatic activity of the Piton des Neiges (Réunion island) Consequence for the primitive crusts. Clay Minerals, 51, 1-16. https://doi.org/10.1180/clm.2018.51

Binley, A., Slater, L. D., Fukes, M., \& Cassiani, G. (2005). Relationship between spectral induced polarization and hydraulic properties of saturated and unsaturated sandstone. Water Resources Research, 41, W12417. https://doi.org/10.1029/2005WR004202

Börner, J. H., Girault, F., Bhattarai, M., Adhikari, L. B., Deldicque, D., Perrier, F., \& Spitzer, K. (2018). Anomalous complex electrical conductivity of a graphitic black schist from the Himalayas of central Nepal. Geophysical Research Letters, 45, 3984-3993. https://doi.org/10.1029/2018GL077178

Bücker, M., Flores Orozco, A., \& Kemna, A. (2018). Electro-chemical polarization around metallic particles-Part 1: The role of diffuse-layer and volume-diffusion relaxation. Geophysics, 83(4), 1-53.

Bücker, M., \& Hördt, A. (2013). Analytical modelling of membrane polarization with explicit parametrization of pore radii and the electrical double layer. Geophysical Journal International, 194(2), 804-813.

Chelidze, T. L., \& Gueguen, Y. (1999). Electrical spectroscopy of porous rocks: A review-I. Theoretical models. Geophysical Journal International, 137(1), 1-15.

Clennell, M. B., Josh, M., Esteban, L., Piane, C. D., Schmid, S., Verrall, M., et al. (2010). The influence of pyrite on rock electrical properties: A case study from NW Australian gas reservoirs. In Society of Petrophysicists and Well-Log Analysts, SPWLA 51st annual logging symposium (pp. 1-13).

Cole, K. S., \& Cole, R. H. (1941). Dispersion and absorption in dielectrics. I. Alternating current characteristics. The Journal of Chemical Physics, 9, 341-351

Davidson, D. W., \& Cole, R. H. (1951). Dielectric relaxation in glycerol, propylene glycol, and n-propanol. The Journal of Chemical Physics, 19(12), 1484-1490.

Einaudi, F., Pezard, P. A., Ildefonse, B., \& Glover, P. (2005). Electrical properties of slow-spreading ridge gabbros from ODP Hole 1105A, SW Indian Ridge. Geological Society, London, Special Publications, 240(1), 179-193.

Fiandaca, G., Madsen, L. M., \& Maurya, P. K. (2018). Re-parameterisations of the Cole-Cole model for improved spectral inversion of induced polarization data. Near Surface Geophysics, 16(4), 385-399.

Florsch, N., Camerlynck, C., \& Revil, A. (2012). Direct estimation of the distribution of relaxation times from induced-polarization spectra using a Fourier transform analysis. Near Surface Geophysics, 10(6), 517-531.

Florsch, N., Revil, A., \& Camerlynck, C. (2014). Inversion of generalized relaxation time distributions with optimized damping parameter Journal of Applied Geophysics, 109, 119-132.

Gautason, B., Egilson, T., Blishke, A., \& Danielsen, P. E. (2007). Krafla: Borun tveggja kjarnahola, KH5 og KH6, veturinn 2006-2007. ISOR, Report in Icelandic.

Ghiorso, M. S., \& Sack, O. (1991). Fe-Ti oxide geothermometry: Thermodynamic formulation and the estimation of intensive variables in silicic magmas. Contributions to Mineralogy and Petrology, 108(4), 485-510.

Ghorbani, A., Camerlynck, C., Florsch, N., Cosenza, P., \& Revil, A. (2007). Bayesian inference of the Cole-Cole parameters from time-and frequency-domain induced polarization. Geophysical Prospecting, 55(4), 589-605.

Gudmundsson, A. (1991). Borun kjarnaholu í Sandabotnaskarð. Report in Icelandic, Orkustofnun.

Gudmundsson, A., Mortensen, A. K., Hjartarson, A., Karlsdóttir, R., \& Ármannsson, H. (2010). Exploration and utilization of the Namafjall high temperature area in North Iceland. World Geothermal Congress.

Haggerty, S. E. (1976). Opaque mineral oxides in terrestrial igneous rocks. Oxide minerals. Short course notes, 3.

Hallof, P., \& Klein, J. (1983). Characterization of electrical properties of metallic mineral deposits. Ontario Geological Survey Open File Report, 5468

Havriliak, S., \& Negami, S. (1966). A complex plane analysis of $\alpha$-dispersions in some polymer systems. Journal of Polymer Science: Polymer Symposia, 14, 99-117.

Hayashi, M. (2004). Temperature-electrical conductivity relation of water for environmental monitoring and geophysical data inversion. Environmental Monitoring and Assessment, 96(1-3), 119-128.

Hördt, A., Bairlein, K., Bielefeld, A., Bücker, M., Kuhn, E., Nordsiek, S., \& Stebner, H. (2016). The dependence of induced polarization on fluid salinity and pH, studied with an extended model of membrane polarization. Journal of Applied Geophysics, 135, 408-417.

Jónsson, S. S., Gudmundsson, A., \& Thordarson, S. (2003). Krafla borun kjarnaholu KH3 milli Jörundar og Háganga. Report in Icelandic, ISOR.

Joseph, S., Ingham, M., \& Gouws, G. (2015). Spectral induced polarization measurements on New Zealand sands-dependence on fluid conductivity. Near Surface Geophysics, 13(2), 169-177.

Júlíusson, B. M., Gunnarsson, I., Matthíasdóttir, K. V., Markússon, S. H., Bjarnason, B., Sveinsson, O. G., et al. (2015). Tackling the challenge of H2S emissions. In Proceedings, World Geothermal Congress (pp. 1-5).

Klein, J. D., \& Sill, W. R. (1982). Electrical properties of artificial clay-bearing sandstone. Geophysics, 47(11), 1593-1605.

Kruschwitz, S. (2007). Assessment of the complex resistivity behaviour of salt affected building materials (Doctoral dissertation), Technischen Universität Berlin. https://doi.org/10.14279/depositonce-1722

Kruschwitz, S., Binley, A., Lesmes, D., \& Elshenawy, A. (2010). Textural controls on low-frequency electrical spectra of porous media. Geophysics, 75(4), WA113-WA123.

Leroy, P., Weigand, M., Mériguet, G., Zimmermann, E., Tournassat, C., Fagerlund, F., et al. (2017). Spectral induced polarization of Na-montmorillonite dispersions. Journal of Colloid and Interface Science, 505, 1093-1110. 
Lesmes, D. P., \& Frye, K. M. (2001). Influence of pore fluid chemistry on the complex conductivity and induced polarization responses of Berea sandstone. Journal of Geophysical Research, 106(B3), 4079-4090.

Lévy, L., Gibert, B., Sigmundsson, F., Flóvenz, O. G., Hersir, G. P., Briole, P., \& Pezard, P. A. (2018). The role of smectites in the electrical conductivity of active hydrothermal systems: Electrical properties of core samples from Krafla volcano, Iceland. Geophysical Journal International, 215(3), 1558-1582.

Libbey, R. B., \& Williams-Jones, A. E. (2013). Sulfide mineralization in the Reykjanes geothermal system, Iceland; Potential applications for geothermal exploration. GRC Trans, 37, 417-424.

Lilova, K. I., Pearce, C. I., Gorski, C., Rosso, K. M., \& Navrotsky, A. (2012). Thermodynamics of the magnetite-ulvöspinel ( $\left.\mathrm{Fe}_{3} \mathrm{O}_{4}-\mathrm{Fe}_{2} \mathrm{TiO}_{4}\right)$ solid solution. American Mineralogist, 97(8-9), 1330-1338.

Macdonald, J. R. (2000). Comparison of the universal dynamic response power-law fitting model for conducting systems with superior alternative models. Solid State Ionics, 133(1-2), 79-97.

Macnae, J. (2015). Comment on: Tarasov, A. \& Titov, K., 2013, On the use of the Cole-Cole equations in spectral induced polarization. Geophysical Journal International, 195, 352-356.

Madsen, L. M., Fiandaca, G., Auken, E., \& Christiansen, A. V. (2017). Time-domain induced polarization-an analysis of Cole-Cole parameter resolution and correlation using Markov Chain Monte Carlo inversion. Geophysical Journal International, 211(3), 1341-1353.

Maurya, P., Fiandaca, G, Christiansen, A., \& Auken, E. (2018). Field-scale comparison of frequency-and time-domain spectral induced polarization. Geophysical Journal International, 214(2), 1441-1466.

Merle, R., Caroff, M., Girardeau, J., Cotten, J., \& Guivel, C. (2005). Segregation vesicles, cylinders, and sheets in vapor-differentiated pillow lavas: Examples from Tore-Madeira Rise and Chile Triple Junction. Journal of Volcanology and Geothermal Research, 141(1-2), 109-122. https://doi.org/10.1016/j.jvolgeores.2004.09.007

Meunier, A., Petit, S., Ehlmann, B. L., Dudoignon, P., Westall, F., Mas, A., et al. (2012). Magmatic precipitation as a possible origin of Noachian clays on Mars. Nature Geoscience, 5(10), 739-743. https://doi.org/10.1038/ngeo1572

Misra, S., Torres-Verdín, C., Revil, A., Rasmus, J., \& Homan, D. (2016). Interfacial polarization of disseminated conductive minerals in absence of redox-active species-Part 1: Mechanistic model and validation. Geophysics, 81(2), E139-E157.

Nordsiek, S., \& Weller, A. (2008). A new approach to fitting induced-polarization spectra. Geophysics, 73(6), F235-F245.

Olhoeft, G. R. (1985). Low-frequency electrical properties. Geophysics, 50(12), 2492-2503.

Parkhomenko, E. I. (1971). Electrification phenomena in rocks. New York: Springer Science \& Business Media.

Pelton, W. H., Ward, S. H., Hallof, P. G., Sill, W. R., \& Nelson, P. H. (1978). Mineral discrimination and removal of inductive coupling with multifrequency IP. Geophysics, 43(3), 588-609.

Pezard, P. A., Howard, J. J., \& Goldberg, D. (1991). Electrical conduction in oceanic gabbros, hole 735B, Southwest Indian Ridge. In Proceedings of the ocean drilling program: Scientific results (pp. 323).

Placencia-Gómez, E. (2015). Spectral induced polarization investigations in presence of metal sulphide minerals: Implications for monitoring the generation of acid mine drainage (Doctoral dissertation), Aalto University - Department of Civil and Environmental Engineering.

Placencia-Gómez, E., \& Slater, L. D. (2016). On the pore water chemistry effect on spectral induced polarization measurements in the presence of pyrite. Journal of Applied Geophysics, 135, 474-485.

Powell, R., \& Powell, M. (1977). Geothermometry and oxygen barometry using coexisting iron-titanium oxides: A reappraisal. Mineralogical Magazine, 41(318), 257-263.

Pridmore, D., \& Shuey, R. (1976). The electrical resistivity of galena, pyrite, and chalcopyrite. American Mineralogist, 61(3-4), 248-259.

Prikryl, J., Marieni, C., Gudbrandsson, S., Aradóttir, E. S., Gunnarsson, I., \& Stefánsson, A. (2018). H2S sequestration process and sustainability in geothermal systems. Geothermics, 71, 156-166.

Revil, A., Florsch, N., \& Mao, D. (2015). Induced polarization response of porous media with metallic particles-Part 1: A theory for disseminated semiconductors. Geophysics, 80, D525-D538.

Revil, A., Mao, D., Shao, Z., Sleevi, M. F., \& Wang, D. (2017). Induced polarization response of porous media with metallic particles-Part 6: The case of metals and semimetals. Geophysics, 82(2), E97-E110.

Revil, A., \& Skold, M. (2011). Salinity dependence of spectral induced polarization in sands and sandstones. Geophysical Journal International, 187(2), 813-824.

Shuey, R. (1975). Semiconducting ore minerals, Developments in Economic Geology (Vol. 4). Amsterdam: Elsevier Scientific Publishing Company.

Slater, L. D., \& Sandberg, S. K. (2000). Resistivity and induced polarization monitoring of salt transport under natural hydraulic gradients Geophysics, 65(2), 408-420.

Stefánsson, A., Arnórsson, S., Gunnarsson, I., Kaasalainen, H., \& Gunnlaugsson, E. (2011). The geochemistry and sequestration of H2S into the geothermal system at Hellisheidi, Iceland. Journal of Volcanology and Geothermal Research, 202(3-4), 179-188.

Sumner, J. S. (1976). Principles of induced polarization for geophysical exploration, Developments in Economic Geology (Vol. 5). Amsterdam: Elsevier Scientific Publishing Company.

Telford, W. M., Geldart, L. P., \& Sheriff, R. E. (1990). Applied geophysics (2nd ed.). Cambridge: Cambridge University Press. https://doi.org/10.1017/CBO9781139167932

Vinegar, H. J., \& Waxman, M. H. (1984). Induced polarization of shaly sands. Geophysics, 49(8), 1267-1287.

Volkmann, J., \& Klitzsch, N. (2015). Wideband impedance spectroscopy from $1 \mathrm{mHz}$ to $10 \mathrm{MHz}$ by combination of four-and two-electrode methods. Journal of Applied Geophysics, 114, 191-201.

Wait, J. R. (1983). Complex conductivity of disseminated spheroidal ore grains. Gerlands Beitr. Geophys, 92, 49-69.

Wait, J. R. (1987). Physical model for the complex resistivity of the earth. Electronics Letters, 23(19), 979-980.

Waxman, M. H., \& Smits, L. J. M. (1968). Electrical conductivities in oil-bearing shaly sands. Journal of Petroleum Science and Engineering, $8,107-122$.

Weigand, M., \& Kemna, A. (2016). Debye decomposition of time-lapse spectral induced polarisation data. Computers \& Geosciences, 86, 34-45.

Weller, A., \& Slater, L. (2012). Salinity dependence of complex conductivity of unconsolidated and consolidated materials: Comparisons with electrical double layer models. Geophysics, 77(5), D185-D198. 
Weller, A., Slater, L., \& Nordsiek, S. (2013). On the relationship between induced polarization and surface conductivity: Implications for petrophysical interpretation of electrical measurements. Geophysics, 78(5), D315-D325.

Wong, J. (1979). An electrochemical model of the induced-polarization phenomenon in disseminated sulfide ores. Geophysics, 44(7), $1245-1265$.

Zimmermann, E., Kemna, A., Berwix, J., Glaas, W., Münch, H. M., \& Huisman, J. A. (2008). A high-accuracy impedance spectrometer for measuring sediments with low polarizability. Measurement Science and Technology, 19(10), 105603.

\section{Erratum}

In the originally published version of this article, the format of numbers in the second to last column of Table 1 were not in proper scientific format. The errors have been corrected, and this may be considered the authoritative version of record. 